\title{
Inhibitor of Apoptosis Protein-1 Regulates Tumor Necrosis Factor-mediated Destruction of Intestinal Epithelial Cells
}

Short title: TNF-induced intestinal epithelial cell death

Thomas Grabinger ${ }^{1}$, Konstantin J. Bode ${ }^{1}$, Janine Demgenski ${ }^{1}$, Carina Seitz ${ }^{1}$, M. Eugenia Delgado $^{1}$, Feodora Kostadinova ${ }^{1}$, Cindy Reinhold ${ }^{1}$, Nima Etemadi ${ }^{2,3}$, Sabine Wilhelm ${ }^{4}$, Matthias Schweinlin ${ }^{4}$, Kay Hänggi ${ }^{5}$, Janin Knop ${ }^{5}$, Christof Hauck ${ }^{6}$, Heike Walles ${ }^{4,7}$, John Silke ${ }^{2,3}$, Harald Wajant ${ }^{8}$, Ueli Nachbur ${ }^{\dagger, \ddagger}$, W. Wei-Lynn Wong ${ }^{\#}$, Thomas Brunner ${ }^{1, \star}$

${ }^{1}$ Chair of Biochemical Pharmacology, Department of Biology, University of Konstanz, Germany

${ }^{2}$ Cell Signaling and Cell Death Division, The Walter and Eliza Hall Institute of Medical Research, Parkville, Australia

${ }^{3}$ Department of Medical Biology, University of Melbourne, Melbourne, Australia

${ }^{4}$ Department of Tissue Engineering and Regenerative Medicine (TERM), University Hospital Würzburg, Würzburg, Germany

${ }^{5}$ Institute of Experimental Immunology, University of Zurich, Switzerland

${ }^{6}$ Chair of Cell Biology, Department of Biology, University of Konstanz, Germany

${ }^{7}$ Translational Center Würzburg, Würzburg branch of the Fraunhofer IGB, Würzburg, Germany

${ }^{8}$ Division of Molecular Internal Medicine, Department of Internal Medicine II, University Hospital Würzburg, Germany 
Acknowledgements: The authors thank A. Glöckner for help with the tissue preparation and sectioning, L. Rösch and P. Widder for technical assistance, and S. Martin for valuable input on the manuscript.

Funding: This work was supported by research grants from the German Science Foundation (DFG) to TB (BR 3369/5-1, INST 38/500-1, INST 38/498-1), from NHMRC to JS (433013, 541902), from the Deutsche Krebshilfe to HW (111703), and the Swiss National Science Foundation to WWW (310030-138085). TG, CS, KB and JS were supported by fellowships from the Research Training Group (RTG1331, DFG), InViTe and NHMRC (541901 \& 1058190), respectively. UN is supported by fellowships from the Swiss National Science Foundation (PA00P3_126249) and the Australian Research Council (FT130100166). This work was made possible through Victorian State Government Operational Infrastructure Support and Australian Government NHMRC IRIISS (\#361646).

Abbreviations: ActD, actinomycin D; ALT, FasL, Fas (CD95) ligand; GalN, Dgalactosamine; IAP, inhibitor of Apoptosis Protein; IEC, intestinal epithelial cells; LPS, lipopolysaccharide; LUBAC, linear ubiquitin assembly complex; MDP, muramyldipeptide; RA, rheumatioid arthritis; RIPK1, receptor-interacting protein kinase 1; Smac, Second mitochondrial activator of caspases; TNF, Tumor Necrosis Factor; TNFR, TNF receptor; TRAIL, TNF-related apoptosis-inducing ligand; TWEAK, TNF-related weak inducer of apoptosis; XIAP, X-linked IAP; YAMC, young adult colonocytes

*Correspondence to: Thomas Brunner, Biochemical Pharmacology, Department of Biology, University of Konstanz, Universitätsstrasse 10, 78457 Konstanz, Germany, Phone: +49 7531 88 5371, Fax: +49 753188 5372, e-mail: thomas.brunner@uni-konstanz.de

Disclosure: The authors declare no conflict of interest 
Author contribution: TG conducted most cellular and in vivo experiments, KB conducted mouse organoid experiments, JD conducted most biochemical experiments, CS, FK, JK and $\mathrm{KH}$ helped with the in vivo experiments, MED conducted in vivo hepatitis experiments, $\mathrm{CR}$ performed lentiviral transduciton, NE and UN performed some of the in vivo experiments, SW, MS and HW conducted experiments with human organoids, JS, HW, UN and WW-LW. provided valuable reagents and contributed to the writing of the manuscript, T.B. designed and supervised the study, and finalized the manuscript. 


\section{Abstract}

Background and aims: Tumor necrosis factor (TNF) is a cytokine that promotes inflammation and contributes to pathogenesis of inflammatory bowel diseases. Unlike other cells and tissues, intestinal epithelial cells undergo rapid cell death upon exposure to TNF, by unclear mechanisms. We investigated the roles of inhibitor of apoptosis proteins (IAPs) in the regulation of TNF-induced cell death in the intestinal epithelium of mice and intestinal organoids.

Methods: RNA from cell lines and tissues and analyzed by quantitative PCR, protein levels were analyzed by immunoblot assays. BIRC2 (also called cIAP1) was expressed upon induction from lentiviral vectors in young adult mouse colon (YAMC) cells. YAMC cells, the mouse colon carcinoma cell line MC38, the mouse macrophage cell line RAW 264.7, or mouse and human organoids were incubated with Smac-mimetic compound LCL161 or recombinant TNF-like weak inducer of apoptosis (TNFSF12) along with TNF, and cell death was quantified. C57BL/6 mice with disruption of Xiap, Birc2 (encodes clAP1), Birc3 (encodes clAP2), Tnfrsf1a, or Tnfrsf1b (Tnfrsf1 $a$ and $b$ encode TNF receptors) were injected with TNF or saline (control); liver and intestinal tissues were collected and analyzed for apoptosis induction by cleaved caspase 3 immunohistochemistry. We also measured levels of TNF and alanine aminotransferase in serum from mice.

Results: YAMC cells, and mouse and human intestinal organoids, died rapidly in response to TNF. YAMC and intestinal crypts expressed lower levels of XIAP, CIAP1, cIAP2, and cFLIP than liver tissue. Smac-mimetics reduced levels of cIAP1 and XIAP in MC38 and YAMC cells, and Smac-mimetics and TWEAK increased TNF-induced cell death in YAMC cells and organoids-most likely by sequestering and degrading cIAP1. Injection of TNF greatly increased levels of cell death in intestinal tissue of clAP1-null mice, compared to wildtype C57BL/6 mice, clAP2-null mice, or XIAP-null mice. Excessive TNF-induced cell death in the intestinal epithelium was mediated TNF receptor 1.

Conclusion: In a study of mouse and human cell lines, organoids, and tissues, we found CIAP1 to be required for regulation of TNF-induced intestinal epithelial cell death and survival. These findings have important implications for the pathogenesis of TNF-mediated enteropathies and chronic inflammatory diseases of the intestine.

Key words: TWEAK, TNF signaling, IBD, mouse model 


\section{Introduction}

Tumor Necrosis Factor- $\alpha$ (TNF) is a cytokine with a broad spectrum of activities. Though predominantly expressed by activated macrophages and dendritic cells, a large variety of different cell types, including epithelial cells in different tissues can produce TNF ${ }^{1,2}$. TNF is one of the first cytokines released during an immune response and generally has important regulatory functions in the control of immunological processes due to its potent proinflammatory properties ${ }^{3}$. When TNF binds to its receptors, TNFR1 and TNFR2, it triggers a series of signaling cascades, generally leading to cellular activation, gene expression and survival ${ }^{4}$. These cellular responses are often initiated by the activation of MAP kinases and $\mathrm{NF}-\kappa \mathrm{B}$. Many of the TNF-induced and NF-kB-regulated target genes are also cytokines with pro-inflammatory activities, including TNF itself, leading to amplification and spreading of the initial inflammatory stimulus ${ }^{5}$. TNF is not only critical during the onset of protective immune responses, but is also involved in the pathogenesis of numerous acute and chronic inflammatory diseases, including inflammatory bowel disease (IBD) ${ }^{6}$ and rheumatoid arthritis (RA) ${ }^{7}$. Thus, TNF is an important therapeutic target, and TNF-neutralizing drugs are successfully used in the treatment of chronic inflammatory diseases, such as RA and IBD.

Although TNF has pro-inflammatory properties promoting cellular activation, proliferation and survival, historically it was the first cell death (necrosis)-promoting cytokine identified due to its ability to induce necrotic cell death in transplanted tumor tissue ${ }^{8}$. It became the founding member of a large family of ligands with diverse functions and activities. Among these, Fas/CD95 ligand (FasL, TNFSF6) and TNF-related apoptosis-inducing ligand (TRAIL, TNFSF10) are particularly well known for their potent cell death-promoting activities ${ }^{9}$. While FasL and TRAIL induce cell death in a large variety of cell lines and/or tissues, most cells and tissues are generally resistant to TNF-induced cell death. This resistance is explained by the fact that TNF-induced NF- $\mathrm{BB}$ activation promotes the expression of various survival proteins (e.g. cFLIP), which prevent TNF-induced apoptosis or necroptosis ${ }^{10,11}$. 
Though TNF alone fails to trigger cell death in most tissues and cell types, there is one important exception, the intestinal epithelium. TNF injection or induction of TNF expression in vivo (e.g. after LPS injection and associated macrophage activation) leads to a very rapid induction of intestinal epithelial cell death, resulting in almost immediate shedding of mature epithelial cells from the villus tip and a somewhat delayed apoptosis of intestinal crypt cells 12. TNF-induced intestinal epithelial cell death is observed during the pathogenesis of a variety of inflammatory diseases, including sepsis, Graft-versus-Host disease ${ }^{13}$, bacterial and viral infections ${ }^{14,15}$ and in particular IBD ${ }^{1,16,17}$. Neutralization of TNF substantially reduces intestinal epithelial cell death under these inflammatory conditions and importantly contributes to improved survival. The reasons for this exquisite sensitivity of intestinal epithelial cells (IECs) to TNF is presently unknown and poorly investigated, but is likely to be very important for the regulation of TNF-induced intestinal immunopathologies, such as IBD.

Inhibitor of apoptosis proteins (IAPS) are a group of proteins related to baculovirus IAP. Mammalian cells express XIAP (X-linked IAP), cIAP1 (cellular IAP1) and 2, NAIP (neuronal IAP) and survivin ${ }^{18,19}$. Most IAPs are directly or indirectly involved in the regulation of cell death. While baculovirus IAP was initially described as a caspase inhibitor, characterization of mammalian IAPs (cIAP1, clAP2 and XIAP) revealed that they can also regulate cell death via their E3 ubiquitin ligase activity (reviewed in ${ }^{19}$ ). In particular clAP1 and 2 are recruited to the receptor complex of various TNF receptor family members, and regulate the activity of other co-recruited signaling proteins by ubiquitination ${ }^{20,21}$. The role of IAPs has been particularly well characterized for TNFR1 signaling. cIAP1 and 2 are recruited to TNFR1 via a TRADD/TRAF2-dependent process and ubiquitinate other signaling proteins of the TNFR1 receptor complex, including RIPK1 (receptor-interacting kinase 1) ${ }^{22,23}$. Absence of clAP1 and 2 , or their pharmacological inhibition by Smac (Second mitochondrial activator of caspases)-mimetics generally results in sensitization of cells to TNF-induced cell death due to inhibition of the induction of protective NF- $\mathrm{kB}$-dependent survival signals, the formation of 
the pro-apoptotic TNFR1-induced complex II, or the RIPK1/RIPK3-dependent induction of necroptosis ${ }^{24,2526}$.

While clAP1 and 2 have overlapping activities, their respective roles in the regulation of TNFinduced cell death in specific cell types and tissues are incompletely understood ${ }^{27}$. In particular their relative contribution to the high sensitivity of IECs to TNF-induced cell death and associated enteropathy has not been explored. Here we show that IECs express only low levels of IAPs compared to liver tissue. Smac-mimetics further sensitize mouse and human IEC to TNF-induced cell death in vitro, and genetic deletion of cIAP1, but not cIAP2 or XIAP, results in massive acceleration of TNF-induced IEC cell death and enteropathy in vivo. TWEAK, that triggers recruitment of CIAP1 and cIAP2 to the TWEAK receptor Fn14 and thus depletes the cytosolic pool of these proteins ${ }^{28,29}$, was also found to sensitize IEC to TNF-induced cell death in vitro and in vivo. Our findings show that clAP1 expression is a limiting and non-redundant factor in the regulation of TNF-induced cell death in the intestinal epithelium. Thus, clAP1-regulated TNF sensitivity likely plays a critical role in TNF-mediated tissue destruction and the pathogenesis of intestinal immunopathologies, such as IBD. 


\section{Materials and Methods}

\section{Mice}

C57BL/6, Tnfrsf1a ${ }^{-/-}$(TNFR1-null), Tnfrsf1 $b^{-/-}$(TNFR2-null) and Xiap ${ }^{-/ 30}$ mice were bred and kept in individually ventilated cages at the central animal facility of the University of Konstanz, Birc2 $2^{--}$(clAP1-null), Birc2 ${ }^{-/} x$ Tnfrsf1a $^{-/-}$and Birc2 ${ }^{-/} x$ Tnfrsf1 $^{-/-}$mice at the animal of the University of Zürich (Switzerland) and Birc3 ${ }^{-/-}$(clAP2-null) mice ${ }^{31}$ at the animal facility of the Walter and Eliza Hall Institute (WEHI) in Melbourne (Australia). As controls wild-type C57BL/6 mice from the respective animal facility were used.

\section{Cell lines}

The conditionally immortalized young adult mouse colon (YAMC) cell line (kind gift of R. Whitehead, Vanderbuilt University) ${ }^{32}$ was maintained at permissive conditions $\left(33^{\circ} \mathrm{C}, 5 \%\right.$ $\mathrm{CO}_{2}$ ) in RPMI 1640 medium (Sigma), supplemented with 5\% fetal calf serum (FCS, PAA), ITS solution (Gibco), $50 \mu \mathrm{g} / \mathrm{ml}$ Gentamicin (Sigma) and $5 \mathrm{U} / \mathrm{ml} \mathrm{mlFN} \gamma$. Six hours prior to treatment, YAMC cell culture was changed to $37^{\circ} \mathrm{C}, 5 \% \mathrm{CO}_{2}$ and medium without $\mathrm{mIFN} \gamma$. The mouse colon carcinoma cell line MC38 was obtained from American type culture collection (ATCC) and cultured in IMDM (Sigma), 10\% FCS, MEM amino-acid solution (Sigma), $4 \mathrm{mM} \mathrm{L-glutamine} \mathrm{and} 50 \mu \mathrm{g} / \mathrm{ml}$ gentamycin (Sigma) at $37^{\circ} \mathrm{C}$ and $5 \% \mathrm{CO}_{2}$. The mouse macrophage cell line RAW 264.7 was obtained from ATCC and maintained in DMEM, $10 \% \mathrm{FCS}$ and $50 \mu \mathrm{g} / \mathrm{ml}$ gentamicin.

\section{Antibodies and reagents}

Antibodies against cleaved caspase 3 (Asp175, \#9661), clAP-1 (\#4952) and Bcl-XL (\#2764) were purchased from Cell Signaling Technology. Antibody against c-Flip (\#ADI-AAP-440E) was purchased from Enzo Life Sciences, anti-tubulin antibody (\#T5168) was purchased from Sigma-Aldrich, EGF (\#315-09), Noggin (\#250-38), IFN $\gamma$ (\#315-05), and R-Spondin-1 (\#12038) were purchased from Peprotech. The Smac mimetic compound LCL161 was kindly 
provided by Norvartis (Basel, Switzerland). Mouse recombinant TWEAK and BV6 was produced as described previously $29,33,34$.

\section{RNA isolation and quantitative PCR}

Total RNA from cell lines and tissue was isolated and reverse transcribed using the High Capacity cDNA Reverse Transcriptions Kit (Applied Biosystems). Quantitative PCR was done on a StepOnePlus Real-Time PCR system (Applied Biosystems) using SYBR green master mix (Applied Biosystems) All gene-specific primers were designed to span an exonexon junction. For CFLIPS $_{S}$ and $C F L I P_{L}$ splice variant-specific primer sequences were used. Gene expression was normalized using $\beta$-actin. Primer sequences used are listed in supplementary Table 1.

\section{Intestinal crypt isolation and organoid culture}

Isolation and culture of mouse and human intestinal crypts were done as described previously ${ }^{35,36}$. Mouse organoids were cultured in 96-well plates, and human organoids in 24-well plates for 3 days $\left(37^{\circ} \mathrm{C}, 5 \% \mathrm{CO}_{2}\right)$ before indicated treatments.

\section{Lentiviral transduction of YAMC cells}

YAMC cells were transduced using a 4-hydroxytamoxyfen-inducibel lentiviral contructs resulting in inducible expression of clAP1 ${ }^{37}$. Cell were cultured with or without $60 \mathrm{nM} 4-$ hydroxytamoxifen for $16 \mathrm{~h}$, exposed to increasing concentrations of TNF and cell death was assessed by MTT assay.

\section{Cell death assay for organoids and cell lines}

MTT (3-(4,5-dimethylthiazol-2-yl)-2,5-diphenyltetrazolium bromide) assays in mouse organoids and cell lines were done as described previously ${ }^{35}$. Cell death in human organoids was detected using an M30 CytoDeath ELISA (VLVbio, Nacka, Sweden) and normalized to the DNA content in the sample. 


\section{Western Blot}

Cells were lysed in NP-40 lysis buffer (150 mM NaCl, 1\% NP-40, 50 mM Tris, pH $8.01 \mathrm{mM}$ EDTA). Concentration of total protein was determined using BCA assay (Pierce) after manufacturer's recommendation. Samples were boiled with SDS-sample buffer $\left(95^{\circ} \mathrm{C}, 5\right.$ min), resolved on SDS-PAGE gels (12\%) and transfered a PVDF membrane. Immunoblot analyses were performed using specific antibodies and visualized with a biomolecular imager (ImageQuant LAS4000, Fujifilm).

\section{Determination of cell death by flow cytometry}

Cells and supernatant of 24 -well plates were harvested, centrifuged at $1000 \times \mathrm{g}, 4^{\circ} \mathrm{C}, 5 \mathrm{~min}$ and resuspended in Annexin-V binding buffer (10 mM HEPES, $150 \mathrm{mM} \mathrm{NaCl}, 5 \mathrm{mM} \mathrm{KCl}, 1$ $\mathrm{mM} \mathrm{MgCl} 2,1.8 \mathrm{mM} \mathrm{CaCl}$ ) with $1 \mu \mathrm{g} / \mathrm{ml}$ FITC-labeled Annexin V. Cell suspension was analyzed using a LSFortessa cytometer (BD Biosciences).

\section{Immunohistochemistry}

Mice were injected with PBS control or $4 \mu \mathrm{g}$ mTNF or hFcTNF for $4 \mathrm{~h}$. Serum was harvested, and tissue from small intestine, large intestine and liver was collected, formalin fixed, dehydrated and paraffin embedded. Apoptotic cells in tissue sections were detected using an anti-cleaved caspase 3 antibody as described previously ${ }^{38}$. Quantification of cleaved caspase 3-positive cells per 100 crypts was done in the small intestine.

\section{Transaminase assay}

For quantitative determination of alanine aminotransferase (ALT) activity in the serum of mice, ALT reagent colorimetric endpoint method kit (Teco Diagnostics) was used after manufacturer's recommendation with 1:5 diluted serum.

\section{TNF ELISA}


TNF in the serum was detected using a commercially available ELISA (BioLegends).

\section{Statistics}

Graph Pad Prism software (GraphPad Software, Ver 5.01) was used for statistical analysis. All experiments were performed in triplicates and repeated at least three times. All values are reported as mean \pm S.D. Where indicated, statistical analysis was evaluated with unpaired two-tailed Student's $t$-tests, with a $P$ value of $<.05$ considered statistically significant. When multiple groups were compared, one-way ANOVA was performed.

\section{Study approval}

All animal experiments complied with animal experimentation regulations of Germany, Switzerland and Australia, and were approved by the Ethics Review Committee of the respective regional council. Experiments using human tissue samples were approved by the institutional ethics committee on human research of the Julius-Maximilians-University Würzburg (study approval number 182/10).

\section{Results}

\section{TNF induces cell death in intestinal epithelial cells in vivo and in vitro}

TNF contributes to the pathogenesis of different inflammatory diseases of the intestine, at least in part via the direct induction of cell death in IECs and associated disruption of the epithelial barrier function ${ }^{39}$. The underlying reason why IECs are so sensitive to TNF is not understood. In order to study the mechanisms of TNF-induced cell death in IECs, we first aimed at establishing an in vitrolex vivo model system recapitulating TNF-induced IEC apoptosis in vivo. Mice were thus injected with a sublethal dose of soluble mouse TNF stimulating particularly TNFR1 ${ }^{40}$. After $6 \mathrm{~h}$ mice were euthanized and tissue sections were analyzed for apoptosis induction by staining for cleaved caspase 3, indicative of ongoing apoptosis in the tissue ${ }^{38}$. While very few cleaved caspase 3-positive cells were detected in 
the small and large intestine of control treated mice, a high frequency of apoptotic cells was detected after TNF injection, in both small and large intestine (Fig. 1A). Cell death detection was particularly prominent in the intestinal crypts. In contrast, TNF injection (in the absence of a tissue-specific sensitizer, such as GalN) failed to promote detectable cleaved caspase 3positive cells in the liver (Fig. 1A).

Since apoptosis was predominantly detected in intestinal crypts, TNF-induced cell death was further studied in ex vivo cultured intestinal organoids ${ }^{35,41}$. Stimulation of these organoids with TNF resulted in a rapid loss of organoid integrity and the appearance of cells with altered morphology, which were propidium iodide positive (Fig. 1B) ${ }^{35}$. The rapid induction of organoid death was further confirmed using a quantitative viability staining method (Fig. 1C).

We further analyzed which TNF receptor mediates cell death in isolated mouse intestinal organoids. In agreement with the in vivo findings ${ }^{42}$ we observed an almost complete abrogation of TNF-induced cell death in Tnfrsf1a-deficient (TNFR1-null) organoids, while organoids from wild-type and Tnfrsf1b-deficient (TNFR2-null) mice showed a dosedependent response, though organoids from TNFR2-null mice exhibited a somewhat reduced cell death (Fig. 1C). This indicates that both TNF receptors mediate cell death in IECs, but predominantly TNFR1. TNF sensitivity was also confirmed in human organoids (Fig. 1D)

We next set out to identify an intestinal cell line, which shows similar responses to TNF as primary IECs. When the intestinal epithelial cell line YAMC (young adult mouse colonocytes) ${ }^{43}$ was exposed to increasing concentrations of TNF, a dose-dependent induction of cell death was detected (Fig. G). In contrast, the macrophage cell line RAW 264.7 failed to die in response to TNF alone, but required sensitization via actinomycin D (Fig. 1H). 
In order to understand the basis of the high sensitivity of IECs to TNF-induced cell death we investigated the relative expression of apoptosis-regulating proteins in primary IEC and YAMC cells in comparison to liver, RAW264.7 and the mouse colorectal tumor cell lines MC38, that are insensitive to TNF-induced cell death. High protein levels of XIAP and clAP1 were detected in liver extracts, whereas crypts expressed relatively high levels of clAP1 but low levels of XIAP. YAMC cells were expressing low levels of both proteins (Fig. 2A). A similar finding was made for $\mathrm{CFLIP}_{\mathrm{S}}$ and $\mathrm{CFLIP}$. In comparison, relatively high expression levels of $\mathrm{Bcl}-\mathrm{x}_{\mathrm{L}}$ were found in all cells and tissues. These findings on a protein level were confirmed by quantitative RT-PCR, where, compared to the liver, intestinal crypts and YAMC cells expressed much lower levels of Xiap, Birc2 (cIAP1), Birc3 (clAP2), and cFlip (Fig. 2B).

\section{Smac-mimetics further sensitize IEC to TNF-induced cell death}

We next assessed the effect of the IAP inhibitor and Smac-mimetics on TNF-induced cell death. As reported previously in other cell types ${ }^{44}$ we observed that LCL161 caused a dosedependent decrease in cIAP1 and XIAP levels in MC38 cells, and confirmed the degradation of the proteins in primary mouse intestinal crypts (Fig. 3A). Treatment of YAMC cells with LCL161 resulted in a profound sensitization to TNF-induced cell death (Fig. 3B) but not chemotherapeutic drug-induced cell death (Fig. 3C and D). This sensitizing effect of IAP inhibition was further confirmed in primary IECs in mouse and human intestinal organoid cultures. Cell death induction by TNF alone was further enhanced by pretreating organoids with LCL161, resp. BV6, while Smac-mimetic alone resulted in only a minimal increase over basal cell death (Fig. 3E and F). Although Smac-mimetics have been previously shown to promote cell death via the activation of the NF- $\mathrm{kB}$ pathway, induction of TNF expression and TNF-mediated cell death ${ }^{25}$, we failed to detect Smac-mimetic-induced TNF in the supernatant of YAMC cells (Suppl. Fig. 1).

\section{TWEAK sensitizes IEC to TNF-induced cell death}


TWEAK (TNFSF12) is a member of the TNF family, which has been found to regulate IEC cell death during T helper 2 (IL-13)-mediated experimental colitis ${ }^{45,46}$. Furthermore, TWEAK has been shown to sensitize cells to FasL- and TNF-induced cell death by promoting the sequestration and degradation of TRAF2 and $\operatorname{clAP} 1{ }^{29,47,48}$. We thus set out to test whether TWEAK-induced cIAP1 degradation could also sensitize IEC to TNF-induced cell death. While TWEAK alone only weakly induced cell death in YAMC cells, it potently enhanced TNF-induced cell death (Fig. 4A). This observation was also confirmed in primary mouse intestinal organoids (Fig. 4C) and a similar observation was made in human organoids (Fig. 4D). In contrast, no sensitization to cisplatin-induced cell death was observed (Fig. 4B). To test the relevance of this finding in vivo, wild-type mice were either injected with TWEAK or TNF alone, or the combination of both. While TWEAK alone failed to induce significant apoptosis induction in intestinal crypts, it significantly enhanced TNF-induced crypt cell apoptosis, as measured by the detection of caspase 3-positive cells (Fig. 4D). These findings were confirmed by the detection of increased cleaved lamin A-positive crypt cells upon cotreatment with TNF and TWEAK, though only a trend towards significant differences was seen (Suppl. Fig. 2)

\section{XIAP is not involved in the regulation of TNF-induced IEC cell death}

Since Smac released from the mitochondria also inhibits XIAP and thereby enhances the mitochondrial apoptosis pathway, we tested the role of XIAP in the regulation of TNF-induced intestinal crypt cell apoptosis. However, TNF-induced apoptosis, as analyzed by the detection of cleaved caspase 3-positive cells, was comparable in both, wild-type and XIAPnull mice (Fig. 5A, B), indicating that regulation of TNF-induced apoptosis by XIAP is not relevant in intestinal crypts. Since XIAP has been implicated in the regulation of death receptor-induced apoptosis of type II cells ${ }^{30}$, we also analyzed TNF-induced cell death induction in the liver. Yet, TNF did not promote a significant increase in alanine transaminase $(A L T)$ in the serum or apoptotic cells in liver tissue (suppl. Fig. 3), indicative of liver damage, 
either in wild-type or in XIAP-null mice (Fig. 5C). In comparison, injection of LPS plus GaIN caused strong liver damage (Fig. 5C and suppl. Fig. 3).

\section{cIAP1 is a critical regulator of TNF-induced IEC apoptosis}

To test the role of cellular IAPs in the regulation of TNF-induced IEC cell death, we analyzed TNF-induced cell death in the absence of clAP1. Injection of clAP1-null mice with TNF resulted in a massive increase of IEC apoptosis, as demonstrated by the high frequency of cleaved caspase 3-positive cells in the small and large intestine of clAP1-null mice in comparison to wild-type mice (Fig. 6A and B). Histological analysis showed that $5 \mathrm{~h}$ post TNF injection massive crypt cell death was observed, and large numbers of mature IECs were shed into the gut lumen, leading to excessive epithelial erosion (Suppl. Fig. 4A and B). Whereas wild-type mice survived $24 \mathrm{~h}$ and longer despite the significant induction of IEC cell death, clAP1-null mice had to be euthanized after $5 \mathrm{~h}$ post TNF injection due to moribundity. Although clAP1-null mice were exquisitely sensitive to TNF, no signs of increased spontaneous apoptosis were evident in control treated mice (Fig. $6 \mathrm{~A}$ and B). Of interest, the mortality of clAP1-null mice appeared to be predominantly mediated by the massive induction of IEC cell death and associated enteropathy, as few signs of liver damage were seen in either wild-type or clAP1-null mice (Fig. 6C and suppl. Fig. 3). The increased sensitivity of clAP1-null intestinal epithelial cells was also confirmed in mouse intestinal organoid cultures, which showed a comparable TNF sensitivity as wild-type organoids treated with LCL161 (Fig. 6D). In contrast, when clAP1 was inducibly expressed in YAMC cells, increased resistance to TNF was observed (Suppl. Fig. 5). An increased endogenous production of TNF due to the activation of the non-canonical NF-kB pathway ${ }^{49}$ could be excluded as a cause for increased IEC cell death, as serum TNF levels as well as intestinal expression levels of TNF mRNA in clAP1-null mice were comparable to that in wild-type and Xiap-deficient mice (Suppl. Fig. 6). To further analyze the respective role of TNF receptors in this massive induction of apoptosis in clAP1-null mice, intestinal tissue damage was analyzed in Birc2 $^{-\alpha} \times$ Tnfrsf1a $^{-/}$(clAP1 $\times$TNFR1-null) and Birc2 $^{--} \times$Tnfrsf1b $^{-/}$(clAP1 $x$ 
TNFR2-null) double-deficient mice. Whereas deletion of Tnfrsf1b had no impact on TNFinduced tissue damage, complete protection was seen in Tnfrsf1a-deficient mice (Fig. 6E and F), supporting again the idea that TNFR1 is the critical cell death-promoting TNF receptor.

\section{cIAP2 is not involved in the regulation of TNF-induced IEC apoptosis}

CIAP1 and 2 have often, but not always, overlapping activities ${ }^{31,49}$. However, when cIAP2null mice were injected with TNF, cell death induction in the intestinal crypts was found to be comparable to that observed in wild-type animals (Fig. 7A and B), indicating that CIAP2 has no crucial role in regulating TNF-induced cell death in IECs. In comparison, approximately a 10-fold higher frequency in TNF-induced crypt cell death was observed in cIAP1-null mice treated at the same time or in a separate experiment (Fig. 7B and 6B). This finding was confirmed in mouse intestinal organoid cultures (Fig. 7C). 


\section{Discussion}

TNF is an important pro-inflammatory and disease-promoting cytokine involved in the pathogenesis of numerous inflammatory disorders. Its role in the pathogenesis of IBD is particularly well studied, and it is an important therapeutic target in Crohn's disease and ulcerative colitis ${ }^{50,51}$. It can either be directly inhibited by neutralizing antibodies or soluble receptors or targeted indirectly by glucocorticoids, which prevent NF-кB activation, TNF expression and associated TNFR-induced inflammatory processes. TNF mediates its deleterious effects via different mechanisms. On one hand TNF promotes the expression of pro-inflammatory cytokines, chemokines and adhesion molecules, mostly via NF-kBdependent processes, and thereby induces the recruitment of immune cells to target tissues. Associated immune cell activation and effector functions in turn often result in excessive tissue damage. However, TNF may also have direct destructive and cytotoxic activities on cells. TNF-induced signaling in IECs leads to activation of the myosin light chain kinase, and associated disruption of tight junctions ${ }^{52}$. The increase in intestinal epithelial barrier permeability often results in penetration of bacteria and bacterial products, stimulation of the immune system and triggering of a vicious cycle of inflammation and tissue destruction. Thus, understanding of signaling processes leading to TNF-mediated IEC cell death are very important in order to develop specific therapies.

Here, we have specifically investigated the mechanism of epithelial damage upon exogenous administration of TNF. In contrast to the liver, the intestinal epithelium is exquisitely sensitive to the pro-apoptotic action of TNF. Confirming previous reports ${ }^{42,53}$, we found that TNFR1 rather than TNFR2 is responsible for transducing the pro-apoptotic signals in IEC. We further provide evidence that clAP1 contributes to the regulation of TNF sensitivity of the intestinal epithelium. While the intestinal epithelium in wild-type mice shows a pronounced sensitivity to TNF-induced cell death, this is drastically enhanced in the absence of clAP1. Confirming the critical role of IAPs in regulating TNF sensitivity we found that treatment of IECs with 
Smac-mimetics also resulted in increased sensitivity to TNF. Similarly, TWEAK, causing ClAP1 sequestration and degradation ${ }^{29,47}$, strongly enhanced TNF-induced cell death in vitro, ex vivo and in vivo.

A remarkable observation of this study is that absence of either cIAP1, cIAP2 or XIAP alone does not result in excessive spontaneous cell death induction, epithelium destruction or inflammation, in particular because in humans mutation of XIAP has been strongly linked to IBD ${ }^{27}$. Though our results show a critical role for clAP1 in controlling TNF sensitivity, absence of either IAPs on its own does not cause chronic stimulation of the NF-kB pathway, associated TNF production, induction of apoptosis or necroptosis, and/or lethality as seen in RIPK1, caspase 8- or FADD-deficient mice ${ }^{54-56}$. However, combined loss of CIAP1 and cIAP2, or cIAP1 and XIAP results in embryonic lethality ${ }^{31}$. Similarly, intestinal epitheliumspecific deletion of RIPK1 does not cause the neonatal lethality observed in the complete RIPK1 knockout, but nevertheless results in massive intestinal inflammation and IEC apoptosis, and death within few weeks of life. This massive IEC apoptosis appears to be due to hyper-responsiveness of the intestinal epithelium to TNF/TNFR1 signaling because combined deletion of TNFR1 prevented the intestinal pathology in both Ripk $1^{-/-}$and Ripk $1^{1 E C-}$ ${ }^{K O}$ mice ${ }^{57,58}$. In this regard it is interesting that RIPK1 is ubiquitinated by CIAP1 and 2 in the TNFR complex, which contributes to resistance to TNF-induced cell death ${ }^{19}$. Alternatively, RIPK1 deficiency could also lead to reduced clAP1 expression levels, as observed by Dannappel ${ }^{58}$ and Takahashi ${ }^{59}$. This could at least explain in part the similarly increased sensitivity of CIAP1- and RIPK1-deficient IECs to TNF-induced cell death. It does, however, not explain why systemic absence of RIPK1 results in neonatal lethality and IEC-specific deletion of Ripk1 in massive spontaneous intestinal inflammation, whereas clAP1 deficiency does not cause death or spontaneous TNF-dependent colitis. RIPK1 induces stabilization of TRAF2 and clAP1, which prevent NIK stabilization and activation of the non-canonical NFKB pathway, potentially leading to TNF production and TNF-induced cell death ${ }^{60}$. Upon loss of Ripk1 IECs produce excessive TNF, which promotes inflammation and apoptosis. Of 
interest, neither an increase in constitutive TNF expression levels nor spontaneous intestinal inflammation was seen in cIAP1-null mice. Thus, deletion of clAP1 or any IAP is likely not sufficient to allow spontaneous NIK activation and TNF production and associated IEC cell death.

While we identified cIAP1 as a critical regulator of TNF-induced IEC cell death, it is surprising to note that Xiap, but not Birc2 (clAP1), gene mutations have been associated with Crohn's disease ${ }^{61}$. Though TNF and associated signaling pathways have been shown to be critically involved in the pathogenesis of IBD, and neutralization of TNF has a significant beneficial effect in Crohn's and colitis patients ${ }^{51}$, we did not observe an increased susceptibility of Xiap-deficient mice to TNF-induced IEC apoptosis. More likely XIAP is involved in innate immune signaling. In this respect, it is interesting that monocytes from patients with Xiap mutations within the RING domain respond in a reduced manner to muramyldipeptide (MDP), in agreement with a recently described role of XIAP in NOD2 signaling ${ }^{62}$. Thus, the role of XIAP in the regulation of IBD may be more related to NOD2 signaling, rather than control of TNF signaling and associated IEC death. This is highlighted by the fact that mutations in Nod2 are among the most frequent disease-associated mutations in IBD patients ${ }^{63}$. Though all three IAPs (XIAP, CIAP1 and 2) are involved in NOD signaling 62, 64, 65, only cIAP1 appears to be critical for TNFR1-induced IEC cell death, resp. survival.

In summary, here we show that clAP1 is critically involved in the regulation of TNF-induced IEC cell death. Thus, processes, which regulate expression and stability of clAP1 may also regulate the pathogenesis of TNF-mediated enteropathies. Our finding is amongst the first demonstration of a unique and limiting role of clAP1 in a given signaling pathway, which is not redundant with cIAP2. Of interest is our observation that TWEAK sensitizes IEC to TNFinduced apoptosis, likely in a clAP1-dependent manner, whereas inhibition of TWEAK signaling in vivo improves experimental colitis ${ }^{66}$, providing further evidence for the proposed mechanism. Since Smac-mimetics likely also sensitize IEC by limiting clAP1-mediated 
protection, the potential use of Smac-mimetics in the clinics, e.g. for sensitizing cancer cells to apoptosis, may also have potential side-effects on the integrity of the intestinal epithelium, particularly in context of simultaneous bacterial infections with high TNF production. 


\section{References}

1. Corazza N, Eichenberger S, Eugster HP, et al. Nonlymphocyte-derived tumor necrosis factor is required for induction of colitis in recombination activating gene (RAG)2(-/-) mice upon transfer of CD4(+)CD45RB(hi) T cells. J Exp Med 1999;190:1479-92.

2. Roulis M, Armaka M, Manoloukos M, et al. Intestinal epithelial cells as producers but not targets of chronic TNF suffice to cause murine Crohn-like pathology. Proc Natl Acad Sci U S A 2011;108:5396-401.

3. Mannel DN, Echtenacher B. TNF in the inflammatory response. Chem Immunol 2000;74:141-61.

4. Wajant $\mathrm{H}$, Pfizenmaier $\mathrm{K}$, Scheurich $\mathrm{P}$. Tumor necrosis factor signaling. Cell Death Differ 2003;10:45-65.

5. Hayden MS, West AP, Ghosh S. NF-kappaB and the immune response. Oncogene 2006;25:6758-80.

6. Maloy KJ, Powrie F. Intestinal homeostasis and its breakdown in inflammatory bowel disease. Nature 2011;474:298-306.

7. Sode J, Vogel U, Bank S, et al. Anti-TNF treatment response in rheumatoid arthritis patients is associated with genetic variation in the NLRP3-inflammasome. PLoS One 2014;9:e100361.

8. Carswell EA, Old LJ, Kassel RL, et al. An endotoxin-induced serum factor that causes necrosis of tumors. Proc Natl Acad Sci U S A. 1975;72:3666-70.

9. Walczak H, Krammer PH. The CD95 (APO-1/Fas) and the TRAIL (APO-2L) apoptosis systems. Exp Cell Res 2000;256:58-66.

10. Van Antwerp DJ, Martin SJ, Kafri T, et al. Suppression of TNF-alpha-induced apoptosis by NF-kappaB. Science 1996;274:787-9.

11. Beg AA, Baltimore D. An essential role for NF-kappaB in preventing TNF-alphainduced cell death. Science 1996;274:782-4.

12. Piguet PF, Vesin C, Donati Y, et al. TNF-induced enterocyte apoptosis and detachment in mice: induction of caspases and prevention by a caspase inhibitor, ZVAD-fmk. Lab Invest 1999;79:495-500.

13. Piguet PF, Grau GE, Allet B, et al. Tumor necrosis factor/cachectin is an effector of skin and gut lesions of the acute phase of graft-vs.-host disease. J Exp Med 1987;166:1280-9.

14. Kim JM, Eckmann L, Savidge TC, et al. Apoptosis of human intestinal epithelial cells after bacterial invasion. J Clin Invest 1998;102:1815-23.

15. Liu F, Feuer R, Hassett DE, et al. Peptide vaccination of mice immune to LCMV or vaccinia virus causes serious CD8 T cell-mediated, TNF-dependent immunopathology. J Clin Invest 2006;116:465-75.

16. Leppkes M, Roulis M, Neurath MF, et al. Pleiotropic functions of TNF-alpha in the regulation of the intestinal epithelial response to inflammation. International immunology 2014;26:509-515.

17. Neurath MF, Fuss I, Pasparakis M, et al. Predominant pathogenic role of tumor necrosis factor in experimental colitis in mice. Eur J Immunol 1997;27:1743-50.

18. Gyrd-Hansen M, Meier P. IAPs: from caspase inhibitors to modulators of NF-kappaB, inflammation and cancer. Nat Rev Cancer 2010;10:561-74.

19. Silke J, Vucic D. IAP family of cell death and signaling regulators. Methods in enzymology 2014;545:35-65.

20. Mahoney DJ, Cheung HH, Mrad RL, et al. Both cIAP1 and clAP2 regulate TNFalphamediated NF-kappaB activation. Proc Natl Acad Sci U S A 2008;105:11778-83.

21. Varfolomeev E, Goncharov T, Maecker H, et al. Cellular inhibitors of apoptosis are global regulators of NF-kappaB and MAPK activation by members of the TNF family of receptors. Sci Signal 2012;5:ra22. 
22. Bertrand MJ, Milutinovic S, Dickson KM, et al. clAP1 and clAP2 facilitate cancer cell survival by functioning as E3 ligases that promote RIP1 ubiquitination. Mol Cell 2008;30:689-700.

23. Vince JE, Pantaki D, Feltham R, et al. TRAF2 must bind to cellular inhibitors of apoptosis for tumor necrosis factor (tnf) to efficiently activate nf-\{kappa\}b and to prevent tnf-induced apoptosis. J Biol Chem 2009;284:35906-15.

24. Li L, Thomas RM, Suzuki H, et al. A small molecule Smac mimic potentiates TRAILand TNFalpha-mediated cell death. Science 2004;305:1471-4.

25. Vince JE, Wong WW, Khan N, et al. IAP antagonists target clAP1 to induce TNFalpha-dependent apoptosis. Cell 2007;131:682-93.

26. Varfolomeev E, Blankenship JW, Wayson SM, et al. IAP antagonists induce autoubiquitination of c-IAPs, NF-kappaB activation, and TNFalpha-dependent apoptosis. Cell 2007;131:669-81.

27. Silke J, Vaux DL. IAP gene deletion and conditional knockout models. Semin Cell Dev Biol 2014.

28. Vince JE, Chau D, Callus B, et al. TWEAK-FN14 signaling induces lysosomal degradation of a clAP1-TRAF2 complex to sensitize tumor cells to TNFalpha. The Journal of cell biology 2008;182:171-84.

29. Wicovsky A, Salzmann S, Roos C, et al. TNF-like weak inducer of apoptosis inhibits proinflammatory TNF receptor-1 signaling. Cell Death Differ 2009;16:1445-59.

30. Jost PJ, Grabow S, Gray D, et al. XIAP discriminates between type I and type II FASinduced apoptosis. Nature 2009;460:1035-9.

31. Moulin M, Anderton H, Voss AK, et al. IAPs limit activation of RIP kinases by TNF receptor 1 during development. EMBO J 2012;31:1679-91.

32. Whitehead RH, VanEeden PE, Noble MD, et al. Establishment of conditionally immortalized epithelial cell lines from both colon and small intestine of adult $\mathrm{H}-2 \mathrm{~Kb}$ tsA58 transgenic mice. Proc Natl Acad Sci U S A 1993;90:587-91.

33. Roos C, Wicovsky A, Muller N, et al. Soluble and transmembrane TNF-like weak inducer of apoptosis differentially activate the classical and noncanonical NF-kappa B pathway. J Immunol 2010;185:1593-605.

34. Muller-Sienerth N, Dietz L, Holtz P, et al. SMAC mimetic BV6 induces cell death in monocytes and maturation of monocyte-derived dendritic cells. PLoS One $2011 ; 6: \mathrm{e} 21556$.

35. Grabinger T, Luks L, Kostadinova F, et al. Ex vivo culture of intestinal crypt organoids as a model system for assessing cell death induction in intestinal epithelial cells and enteropathy. Cell Death Dis 2014;5:e1228.

36. Schweinlin M, Wilhelm S, Schwedhelm I, et al. Development of an Advanced Primary Human In Vitro Model of the Small Intestine. Tissue Eng Part C Methods 2016;22:873-83.

37. Feltham R, Moulin M, Vince JE, et al. Tumor necrosis factor (TNF) signaling, but not TWEAK (TNF-like weak inducer of apoptosis)-triggered cIAP1 (cellular inhibitor of apoptosis protein 1) degradation, requires cIAP1 RING dimerization and E2 binding. The Journal of biological chemistry 2010;285:17525-36.

38. Jakob S, Corazza N, Diamantis E, et al. Detection of apoptosis in vivo using antibodies against caspase-induced neo-epitopes. Methods 2008;44:255-261.

39. Suenaert $P$, Bulteel V, Lemmens $L$, et al. Anti-tumor necrosis factor treatment restores the gut barrier in Crohn's disease. Am J Gastroenterol 2002;97:2000-4.

40. Peschon JJ, Torrance DS, Stocking KL, et al. TNF receptor-deficient mice reveal divergent roles for p55 and p75 in several models of inflammation. J Immunol 1998;160:943-52.

41. Sato T, Vries RG, Snippert HJ, et al. Single Lgr5 stem cells build crypt-villus structures in vitro without a mesenchymal niche. Nature 2009;459:262-5.

42. Piguet PF, Vesin C, Guo J, et al. TNF-induced enterocyte apoptosis in mice is mediated by the TNF receptor 1 and does not require p53. European journal of immunology 1998;28:3499-505. 
43. Noti M, Corazza N, Mueller C, et al. TNF suppresses acute intestinal inflammation by inducing local glucocorticoid synthesis. J Exp Med 2010;207:1057-66.

44. Yabal M, Muller N, Adler H, et al. XIAP restricts TNF- and RIP3-dependent cell death and inflammasome activation. Cell Rep 2014;7:1796-808.

45. Kawashima R, Kawamura YI, Oshio T, et al. Interleukin-13 damages intestinal mucosa via TWEAK and Fn14 in mice-a pathway associated with ulcerative colitis. Gastroenterology 2011;141:2119-2129 e8.

46. Son A, Oshio T, Kawamura YI, et al. TWEAK/Fn14 pathway promotes a T helper 2type chronic colitis with fibrosis in mice. Mucosal immunology 2013;6:1131-42.

47. Vince JE, Chau D, Callus B, et al. TWEAK-FN14 signaling induces lysosomal degradation of a clAP1-TRAF2 complex to sensitize tumor cells to TNFalpha. J Cell Biol 2008;182:171-84.

48. Geserick P, Hupe M, Moulin M, et al. Cellular IAPs inhibit a cryptic CD95-induced cell death by limiting RIP1 kinase recruitment. J Cell Biol 2009;187:1037-54.

49. Silke J, Meier P. Inhibitor of apoptosis (IAP) proteins-modulators of cell death and inflammation. Cold Spring Harbor perspectives in biology 2013;5.

50. Nielsen $\mathrm{OH}$. New strategies for treatment of inflammatory bowel disease. Front Med (Lausanne) 2014;1:3.

51. Atreya R, Neurath MF. New therapeutic strategies for treatment of inflammatory bowel disease. Mucosal Immunol 2008;1:175-82.

52. Ma TY, Boivin MA, Ye D, et al. Mechanism of TNF-\{alpha\} modulation of Caco-2 intestinal epithelial tight junction barrier: role of myosin light-chain kinase protein expression. Am J Physiol Gastrointest Liver Physiol 2005;288:G422-30.

53. Van Hauwermeiren F, Armaka M, Karagianni N, et al. Safe TNF-based antitumor therapy following p55TNFR reduction in intestinal epithelium. The Journal of clinical investigation 2013;123:2590-603.

54. Kaiser WJ, Upton JW, Long AB, et al. RIP3 mediates the embryonic lethality of caspase-8-deficient mice. Nature 2011;471:368-72.

55. Dillon CP, Weinlich R, Rodriguez DA, et al. RIPK1 blocks early postnatal lethality mediated by caspase-8 and RIPK3. Cell 2014;157:1189-202.

56. Welz PS, Wullaert A, Vlantis K, et al. FADD prevents RIP3-mediated epithelial cell necrosis and chronic intestinal inflammation. Nature 2011;477:330-4.

57. Rickard JA, O'Donnell JA, Evans JM, et al. RIPK1 regulates RIPK3-MLKL-driven systemic inflammation and emergency hematopoiesis. Cell 2014;157:1175-88.

58. Dannappel M, Vlantis K, Kumari S, et al. RIPK1 maintains epithelial homeostasis by inhibiting apoptosis and necroptosis. Nature 2014;513:90-4.

59. Takahashi N, Vereecke L, Bertrand MJ, et al. RIPK1 ensures intestinal homeostasis by protecting the epithelium against apoptosis. Nature 2014;513:95-9.

60. Gentle IE, Wong WW, Evans JM, et al. In TNF-stimulated cells, RIPK1 promotes cell survival by stabilizing TRAF2 and clAP1, which limits induction of non-canonical NFkappaB and activation of caspase-8. The Journal of biological chemistry 2011;286:13282-91.

61. Damgaard RB, Gyrd-Hansen M. Inhibitor of apoptosis (IAP) proteins in regulation of inflammation and innate immunity. Discov Med 2011;11:221-31.

62. Damgaard RB, Nachbur U, Yabal M, et al. The ubiquitin ligase XIAP recruits LUBAC for NOD2 signaling in inflammation and innate immunity. Molecular cell 2012;46:74658.

63. Ogura $\mathrm{Y}$, Bonen DK, Inohara N, et al. A frameshift mutation in NOD2 associated with susceptibility to Crohn's disease. Nature 2001;411:603-6.

64. Pedersen J, LaCasse EC, Seidelin JB, et al. Inhibitors of apoptosis (IAPs) regulate intestinal immunity and inflammatory bowel disease (IBD) inflammation. Trends Mol Med 2014;20:652-65.

65. Bertrand MJ, Doiron K, Labbe K, et al. Cellular inhibitors of apoptosis clAP1 and clAP2 are required for innate immunity signaling by the pattern recognition receptors NOD1 and NOD2. Immunity 2009;30:789-801. 
66. Dohi T, Burkly LC. The TWEAK/Fn14 pathway as an aggravating and perpetuating factor in inflammatory diseases: focus on inflammatory bowel diseases. Journal of leukocyte biology 2012;92:265-79.

Author names in bold designate shared co-first authorship. 


\section{Figures and figure legends}

Fig. 1: TNF-induced cell death in intestinal epithelial cells in vivo and in vitro.

(A) Wild-type mice were injected with PBS or TNF for 4h, and apoptosis in small and large intestine and liver was detected using cleaved caspase 3 immunohistochemistry $(n=12$ mice per group) Scale bar $=150 \mu \mathrm{m}$. (B) Representative microscopic (phase contrast and Hoechst/propidium iodide staining) images of PBS- and TNF-treated mouse intestinal organoids. Scale bar $=150 \mu \mathrm{m}$. (C) Organoids from wild-type (WT), Tnfrsf1a $a^{-/-}$(TNFR1-null)

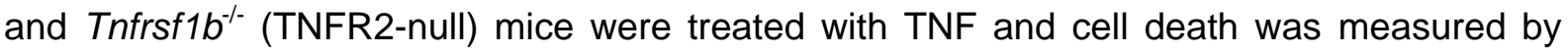
MTT reduction (mean $\pm S D$ of triplicates, $n=3$ ). (D) Human organoids were treated with increasing doses of TNF and cell death was analyzed by M30 ELISA (mean \pm SD of triplicates, $n=3$ ). (E) YAMC cells were treated with indicated doses of TNF and cell death was assessed by MTT. Mean +/- SD of triplicate of representative experiments are shown (n = 4). (F) RAW 264.7 macrophage cells were either pretreated with ActD (60 ng/ml) or PBS, and TNF-induced cell death was measured by MTT reduction (mean \pm SD of triplicates, $n=$ 2).

\section{Fig. 2: IAP expression in intestinal epithelial cells.}

Protein (A) and mRNA (B) expression of the indicated genes in liver, isolated crypts and the cell lines YAMC, MC38 and RAW 264.7. Representative immunoblots of 3 independent experiments are shown. Mean values \pm SD of samples from three individual mice are shown for qPCR $(\mathrm{n}=2$ ). Birc2, clAP1; Birc3, clAP2; Cflar (short), cFLIP ; Cflar (long), cFLIPL; Vil-1, Villin.

\section{Fig. 3: The Smac-mimetic LCL161 sensitizes IECs to TNF-induced cell death.}

(A) MC38 and isolated crypts were treated with the indicated concentrations of LCL161 for $2 h$, and protein levels of clAP1 and XIAP were detected by immunoblotting $(n=3)(B)$ YAMC cells were pretreated with indicated concentrations of LCL161 for $2 \mathrm{~h}$, and then stimulated 
with buffer control or TNF (30 ng/ml). (C-D) YAMC cells were pretreated with indicated concentrations of LCL161, and stimulated with the chemotherapeutic agents cisplatin (C) or irinotecan (D) (Mean values \pm SD of triplicates, $n=2$ ). $(E)$ Mouse organoids were pre-treated with LCL161 (30 nM), followed by stimulation with TNF (30 ng/ml). Organoid cell death was measured by MTT reduction. ${ }^{* * *} P<.001$. Mean values \pm SD of triplicates, $\mathrm{n}=3$. (F) Human organoids were pre-treated with BV6, then stimulated with TNF $(1 \mathrm{ng} / \mathrm{ml})$, and cell death was analyzed by M30 ELISA. Mean values \pm SD of triplicates, $n=3$

\section{Fig. 4: TWEAK sensitizes IECs to TNF-induced cell death}

YAMC cells were pretreated with indicated concentrations of TWEAK, and then treated with either TNF (A) or the chemotherapeutic agent cisplatin (B). Cell death was measured by MTT reduction. Mean values \pm SD of triplicates are shown $(n=3)$. (C), (D) Mouse Organoids (C) and human organoids (D) were pretreated with TWEAK, and stimulated with PBS or TNF. Mean values \pm SD of triplicates are shown $(n=2)(E)$ Mice were injected with PBS or TWEAK $(200 \mu \mathrm{g})$, and PBS or $10 \mu \mathrm{g}$ TNF ( $n=3$ mice per group). The number of cleaved caspase 3 -positive cells per 100 crypts was quantified. ${ }^{* *}, P<.01,{ }^{*} P<.05$.

\section{Fig. 5: XIAP is not involved in the regulation of TNF-induced IEC cell death}

(A) Wild-type (WT) and $\mathrm{Xiap}^{-/}$mice were injected with PBS or TNF $(4 \mu \mathrm{g})$ and cleaved caspase 3-positive cells in the small intestine was analyzed $(n=4$ per group; scale bar $=150$ $\mu \mathrm{m})$. Inserts show magnification. (B) Quantification of cleaved caspase 3-positive cells in intestinal crypts. ${ }^{* *} P<.01$, n.s. $=$ not significant. (C) Serum transaminase (ALT) activity of TNF treated WT and Xiap ${ }^{-/}$mice ( $n=3$ per group). Serum from LPS plus GalN-treated mice served as positive control. Individual data points and mean values are shown.

\section{Fig. 6: cIAP1 is a critical regulator of TNF-induced IEC apoptosis}

(A) Wild-type (WT) or clAP1-null $\left(\right.$ Birc2 $\left.^{--}\right)$mice were treated with PBS or TNF $(4 \mu \mathrm{g})$, and apoptosis in small and large intestine was detected using cleaved caspase 3 
immunohistochemistry ( $\mathrm{n}=6$ per group; scale bar $=150 \mu \mathrm{m})$. Insets show magnifications. (B) Apoptotic cells within the crypt region of tissue from the same experiment were quantified. ${ }^{*} P<.05,{ }^{* *} P<.01$. Mean values and individual data points are shown. (C) Serum transaminase activity of TNF-treated WT and clap $1^{-1-}$ mice ( $\mathrm{n}=3$ per group). ALT values of LPS plus GalN-treated WT mice served as positive control for excessive liver damage. Mean values and individual data points are shown. (D) Organoids from WT or clAP1-null $\left(\right.$ Birc2 $\left.^{--}\right)$mice were treated with indicated concentrations of TNF. WT organoids were also pretreated with LCL161 (60 nM). Cell death was measured by MTT reduction. Mean values of triplicates $\pm S D$ of a representative experiment are shown $(n=2)$. (E) WT, Birc2 $^{-/}$(clAP1-null), Birc2 ${ }^{-/}$Tnfrsf1a $^{-/-}$(clAP1-null TNFR1-null), and Birc2 ${ }^{-/}$Tnfrsf1b $^{-/-}$(clAP1null TNFR2-null) mice were injected with $4 \mu \mathrm{g}$ TNF and cell death in small intestine was detected using cleaved caspase 3 immunohistochemistry. (F) Quantification of experiment shown in $(E)\left(n=3\right.$ per TNF-treated group. ${ }^{*} p<.05,{ }^{* *} p<.01$.

\section{Fig. 7: cIAP2 is not critical for TNF-mediated IEC cell death}

(A) Cleaved caspase 3 immunohistochemistry of small and large intestinal tissue sections from TNF $(4 \mu \mathrm{g})$ or PBS-injected wild-type (WT) and Birc3 ${ }^{/-}$(clAP2-null) mice ( $\mathrm{n}=4$ per group; scale bar $=150 \mu \mathrm{m})$. (B) Quantification of apoptotic crypt cells in small intestinal

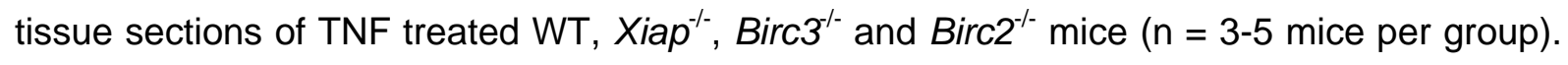
Individual data points and mean values are shown. ${ }^{* *} P<.01$, n.s. $=$ not significant. (C) Intestinal organoids of WT, Birc2 ${ }^{--}$and $B i r c 3^{-/-}$mice were treated with indicated concentrations of TNF. Cell death was determined by MTT reduction. Mean values of triplicates $\pm S D$ of a representative experiment $(n=2)$ are shown. 
A

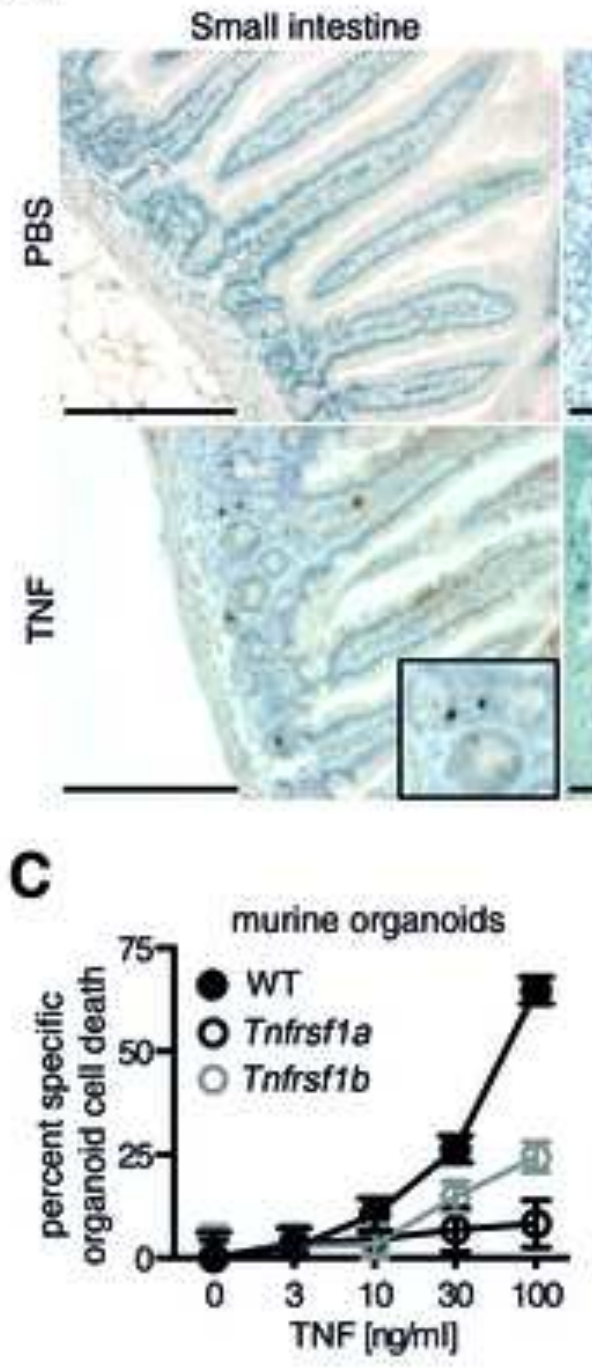

Large intestine

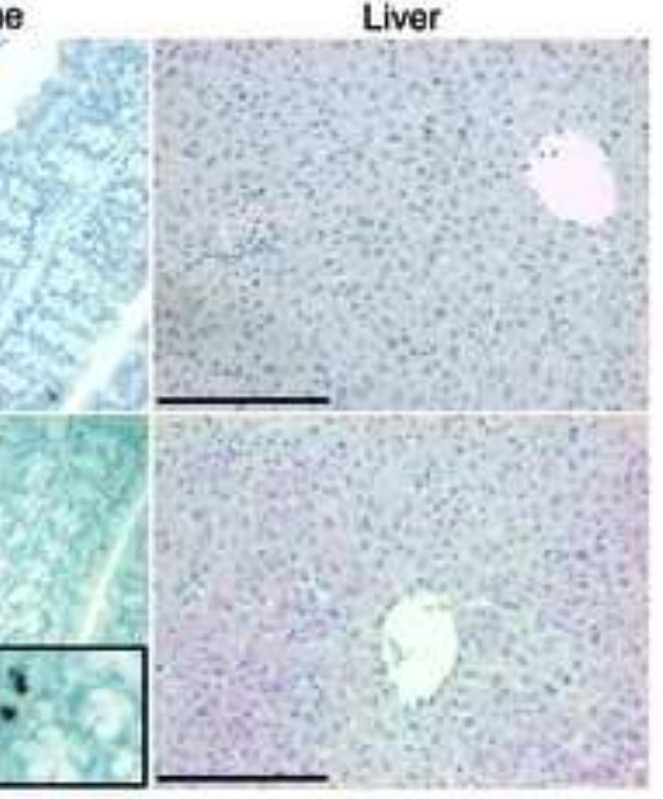

B

murine organoid

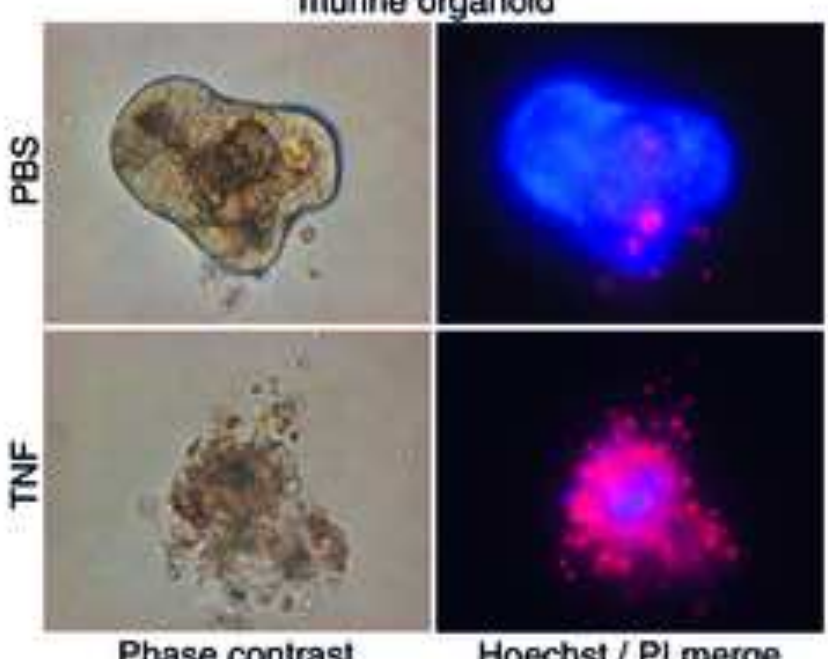

Phase contrast
Hoechst / PI merge

F

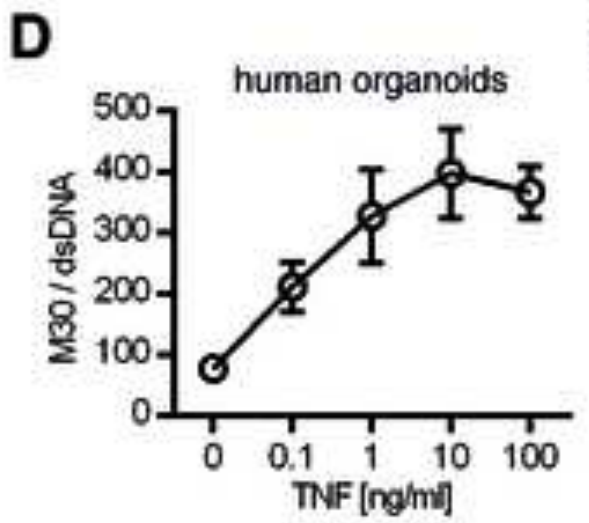

E

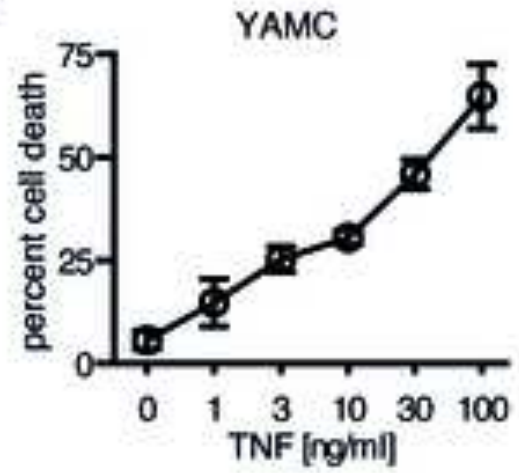

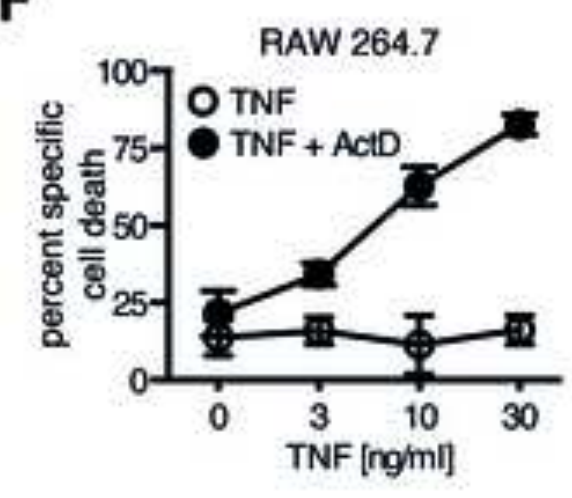




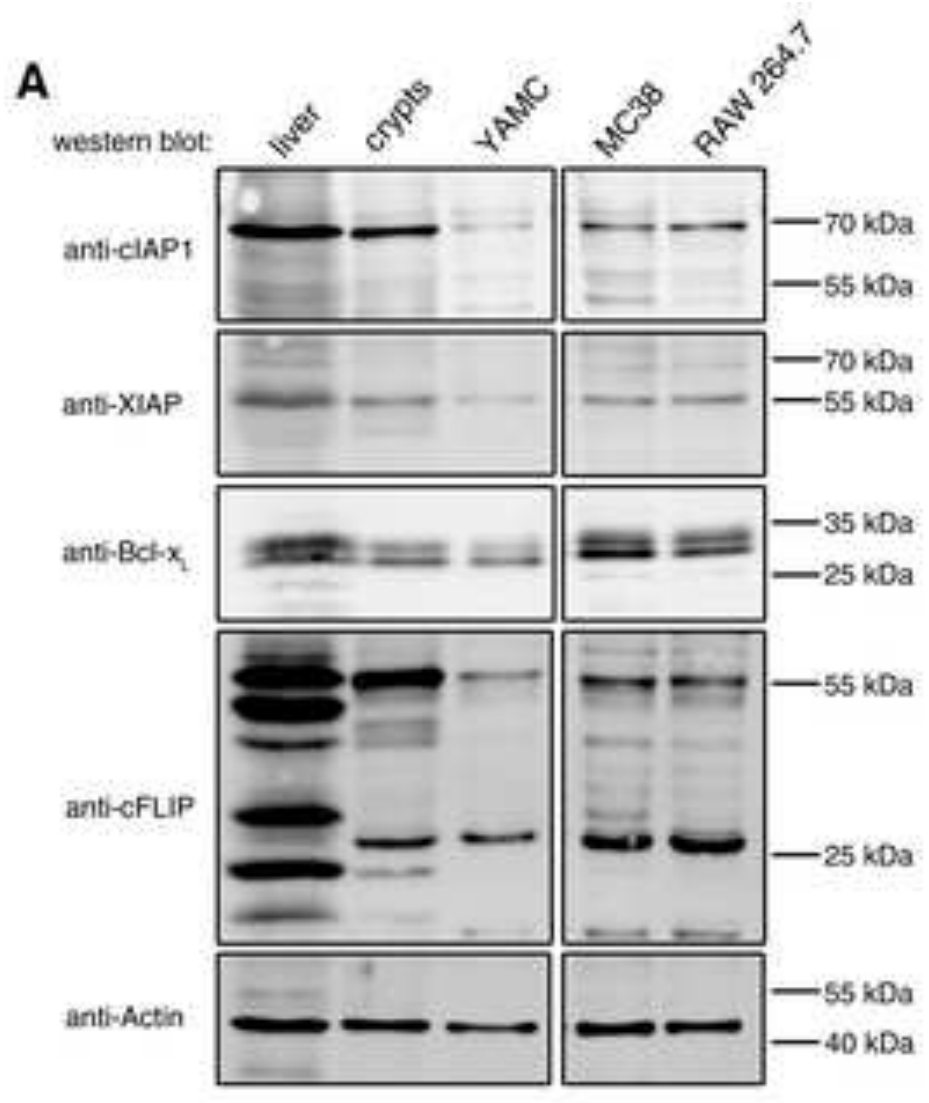

B
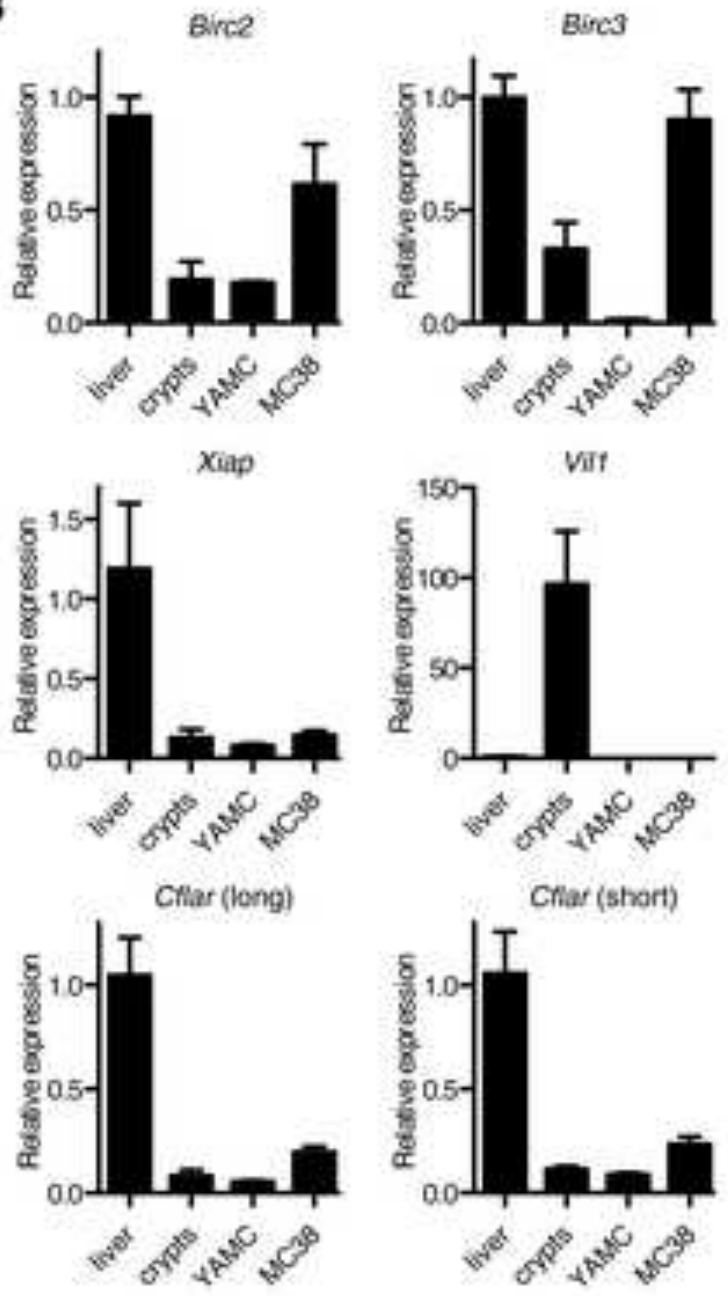

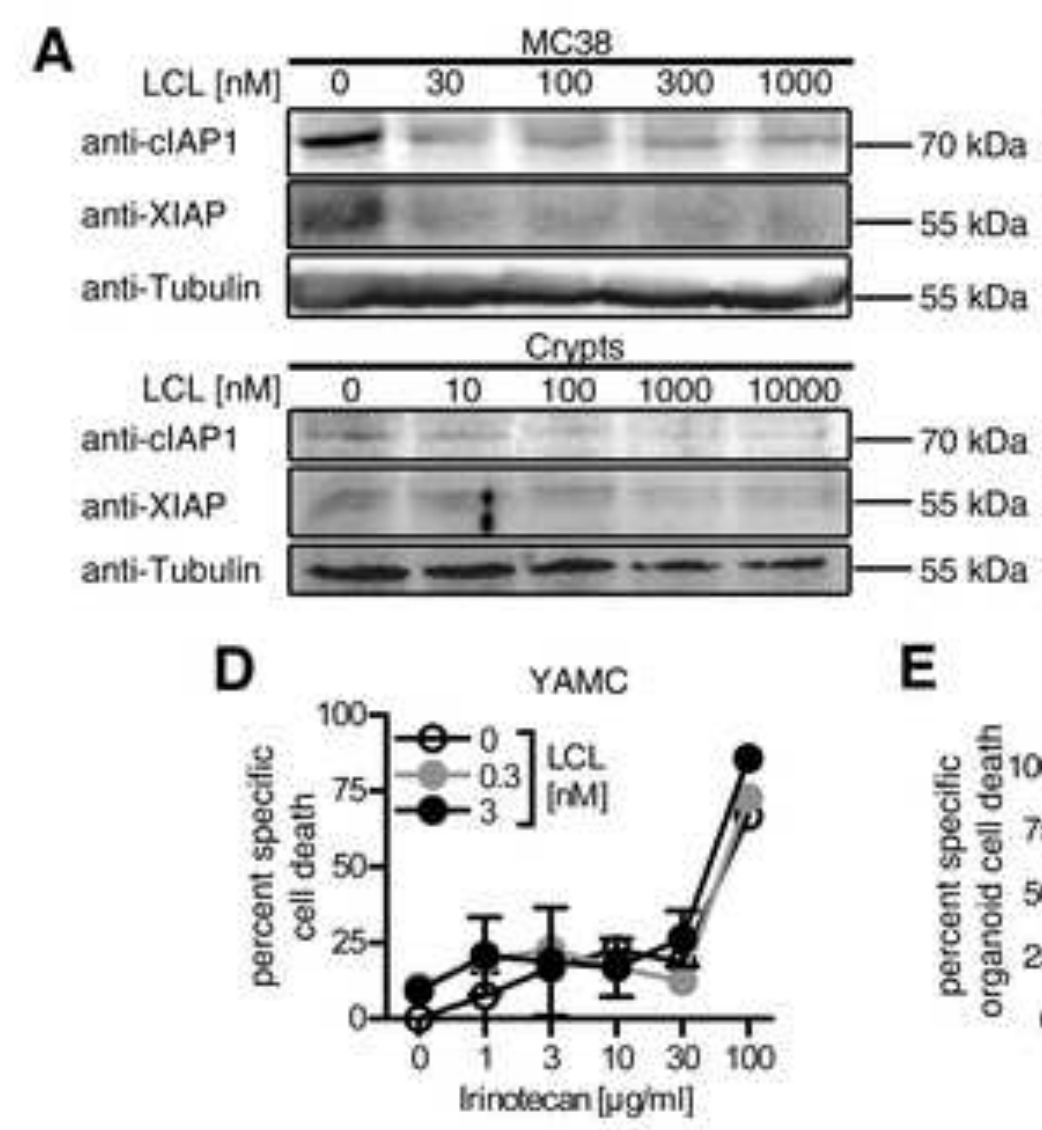

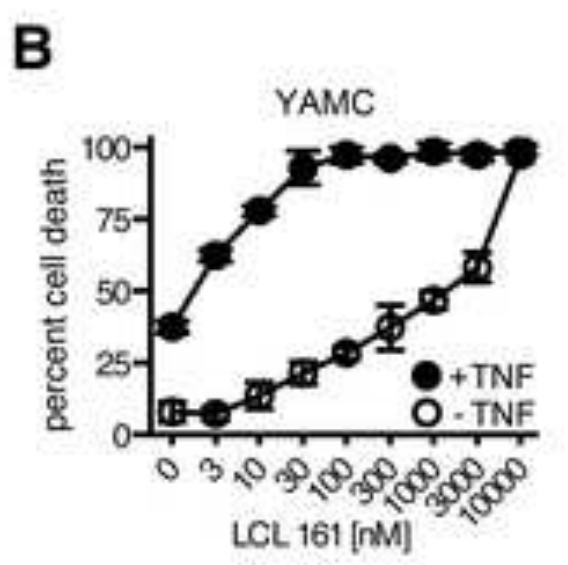

C

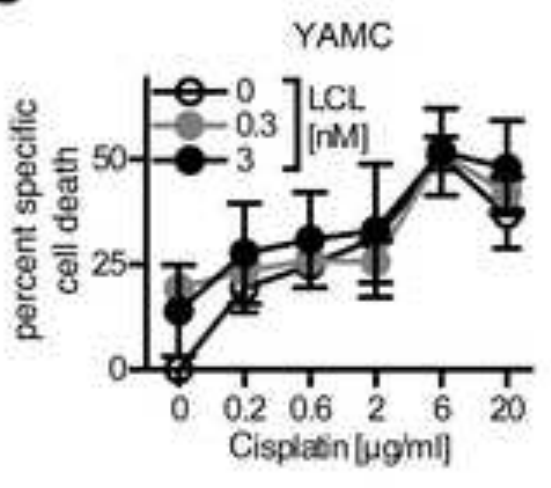

E

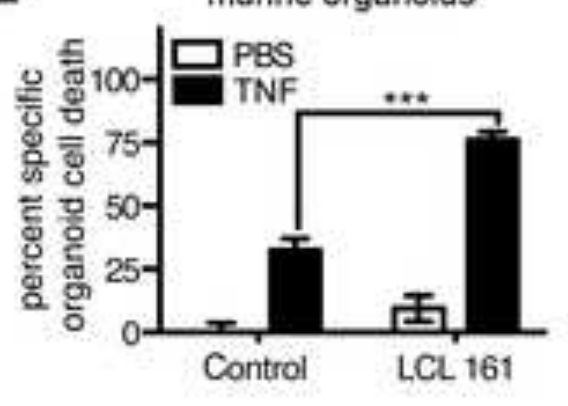

F

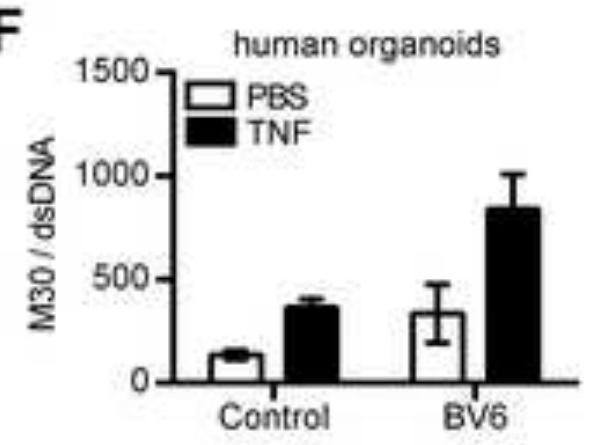


A

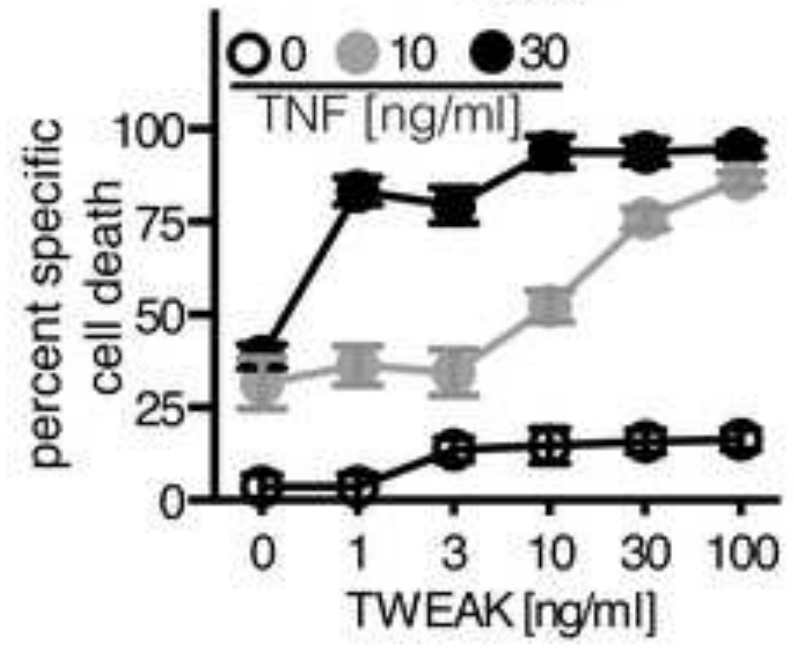

C

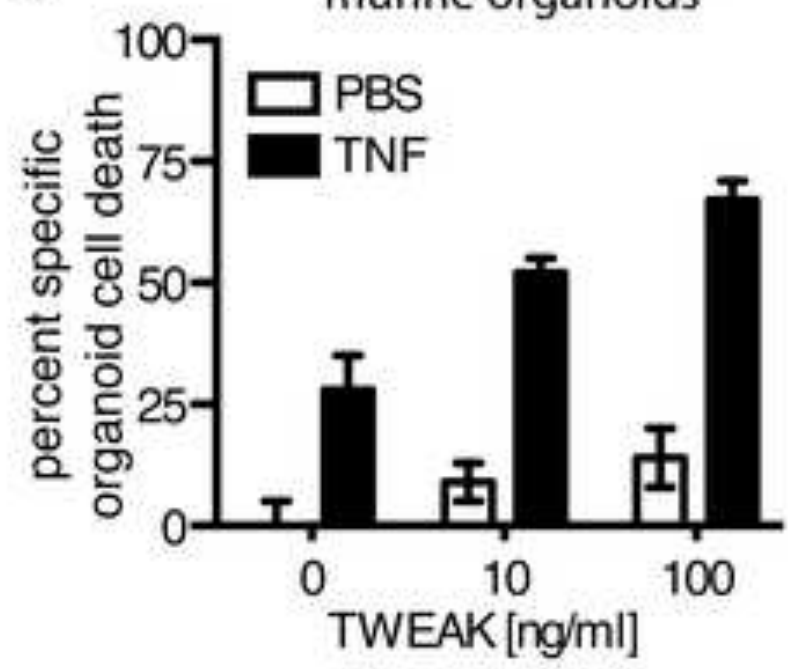

E

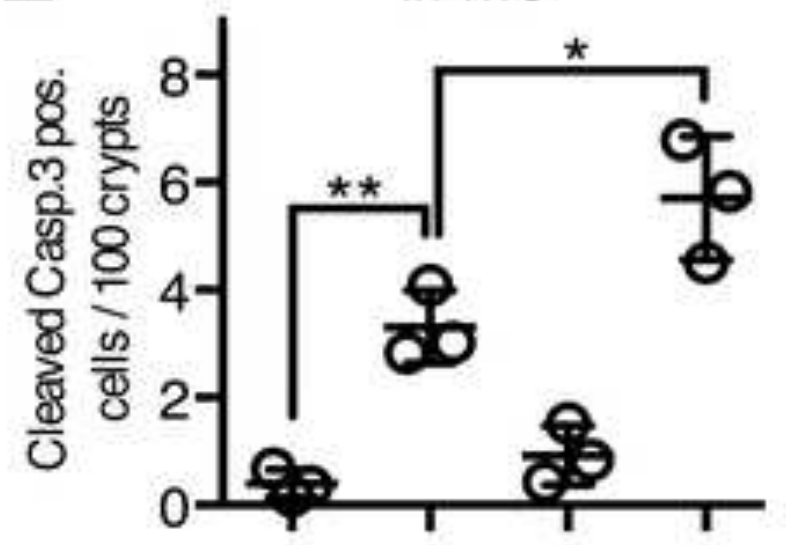

$\beta^{5}$

In vivo
B

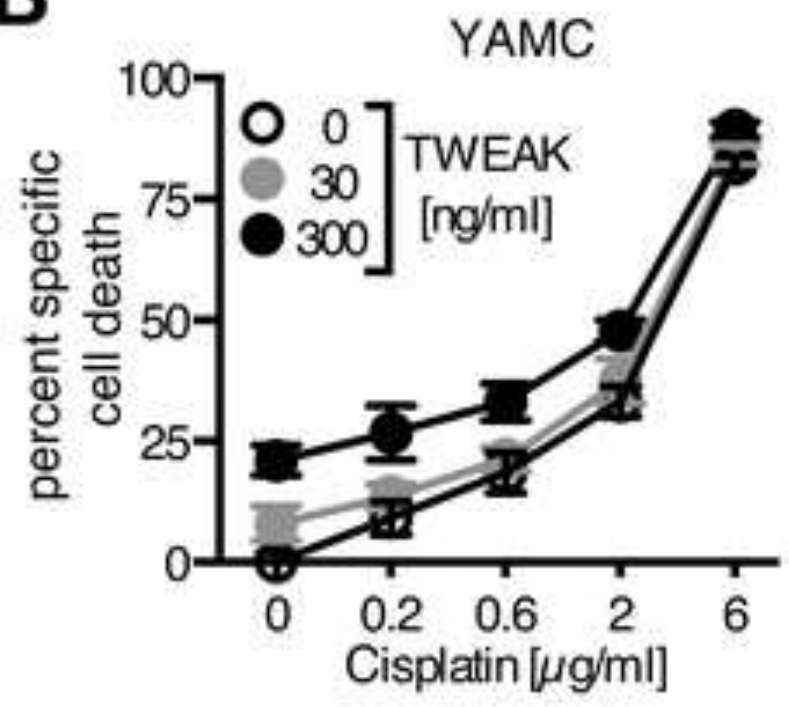

D

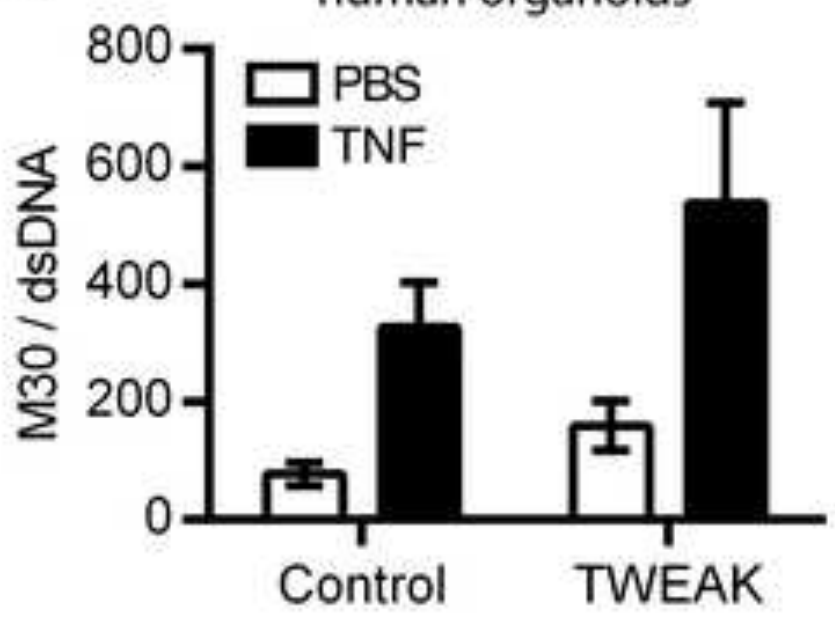

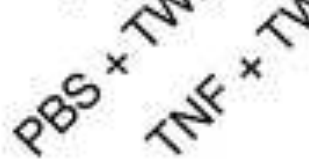


A

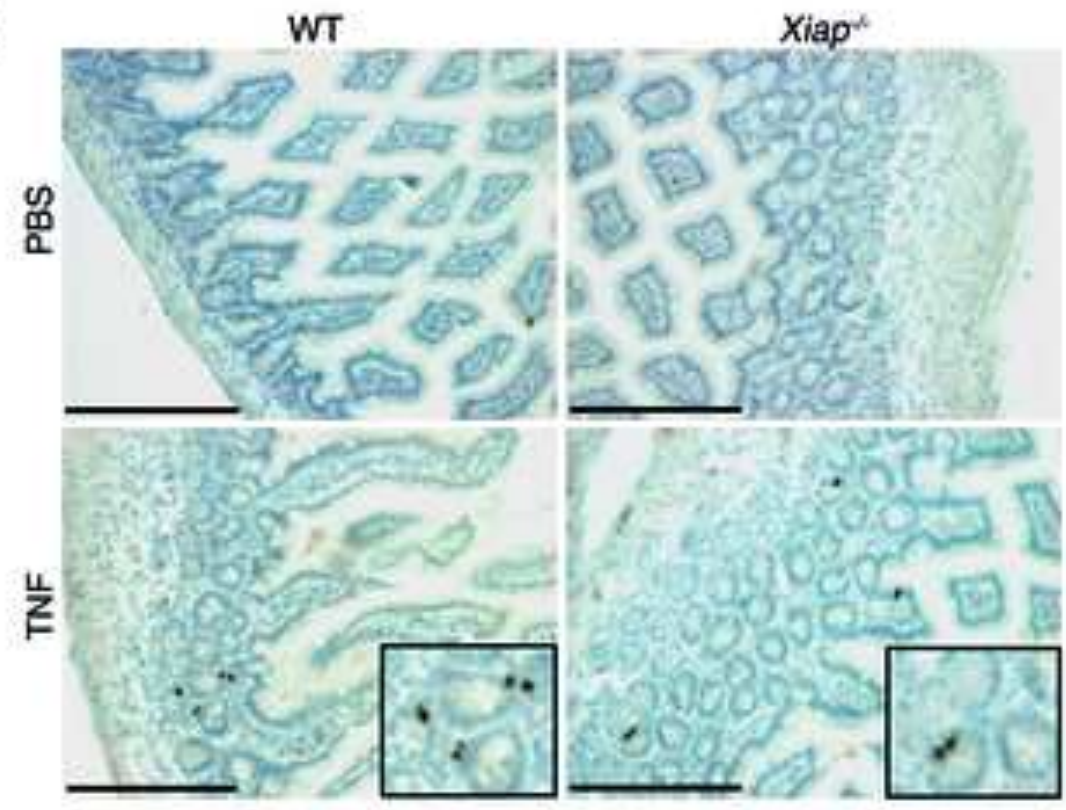

B

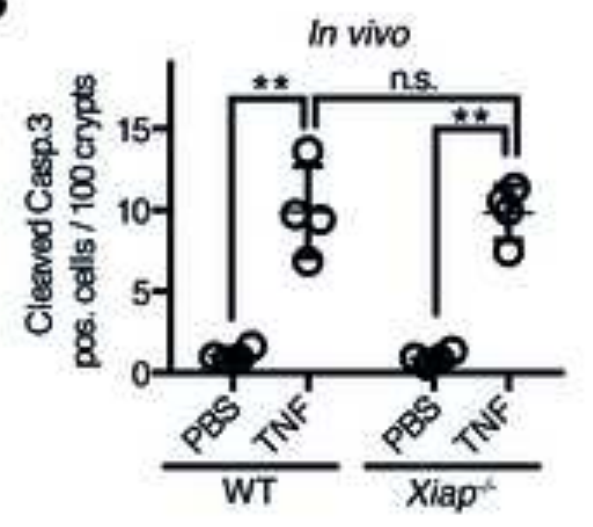

C

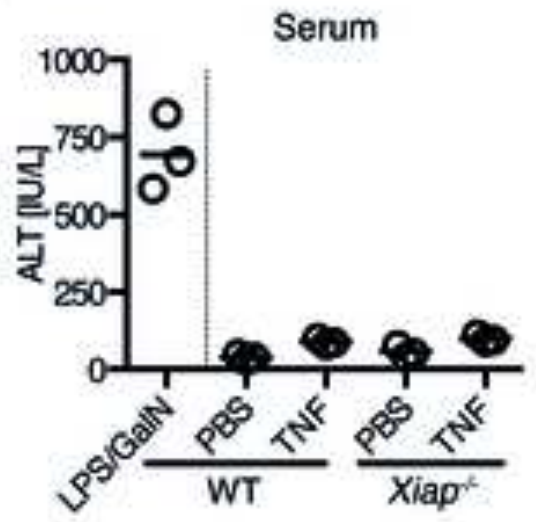


A

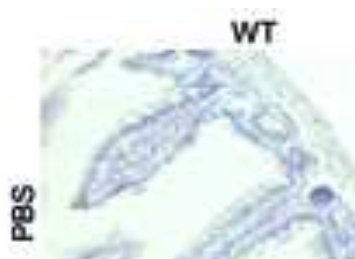

8

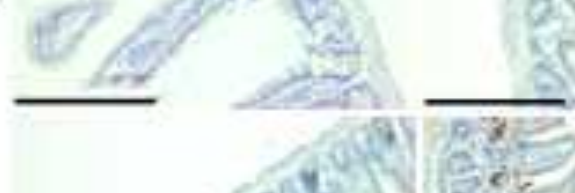

$\frac{u}{z}$

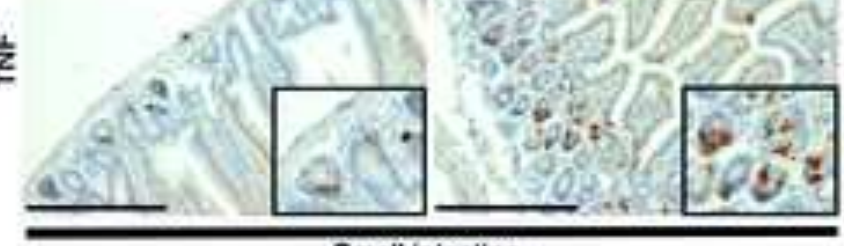

B

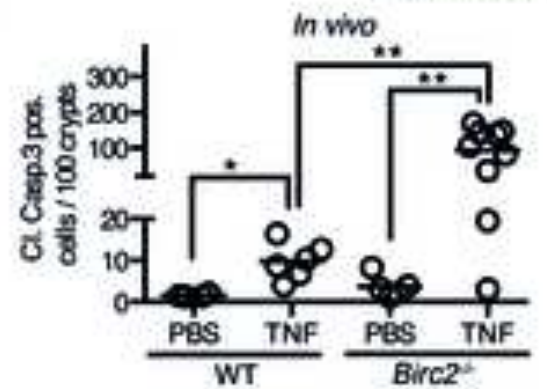

Birce

C

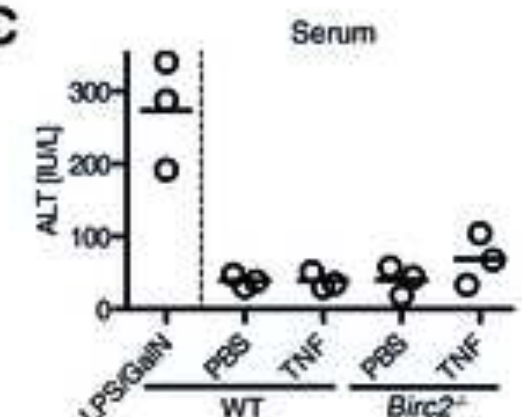

WT

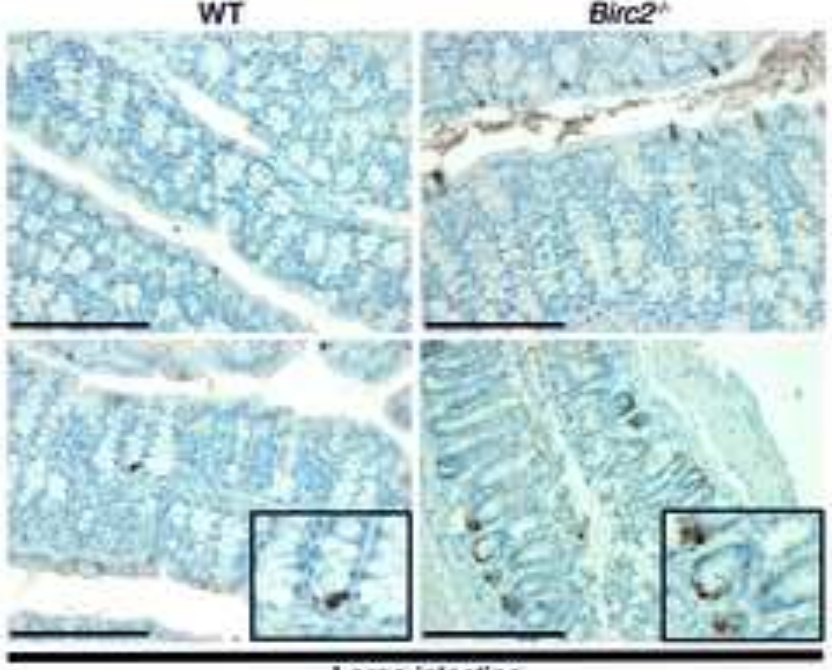

Large imestine

D ${ }_{100}$ murine organolds

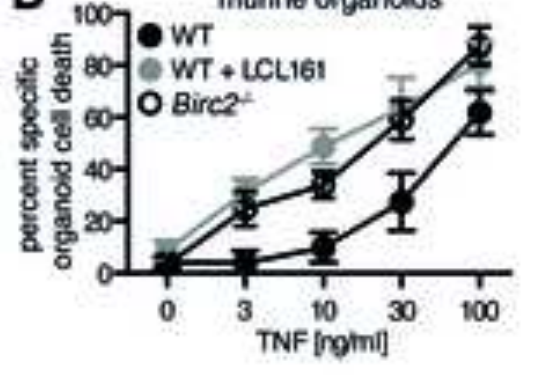

E

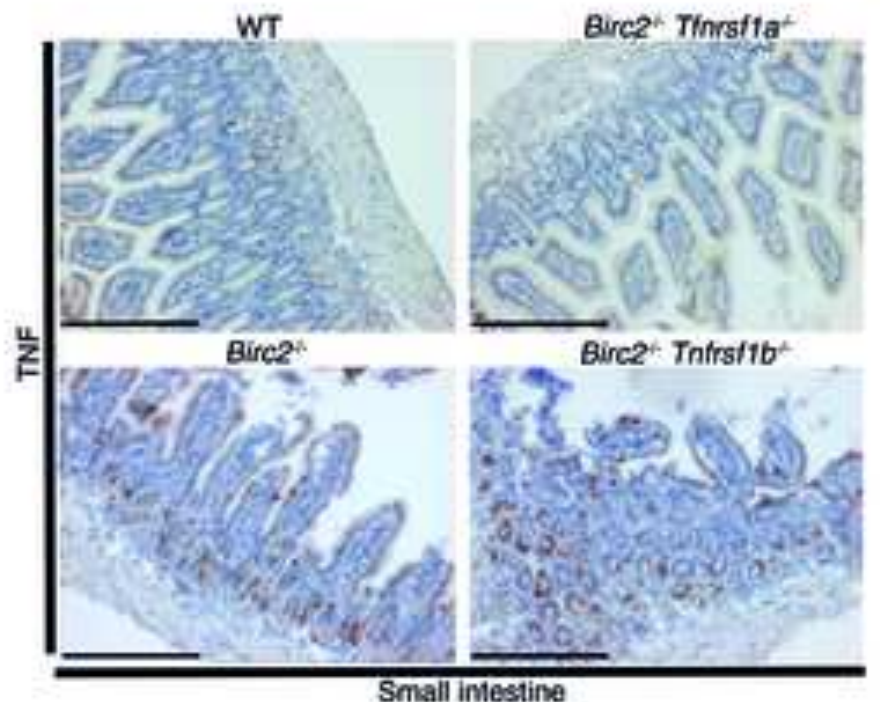

F

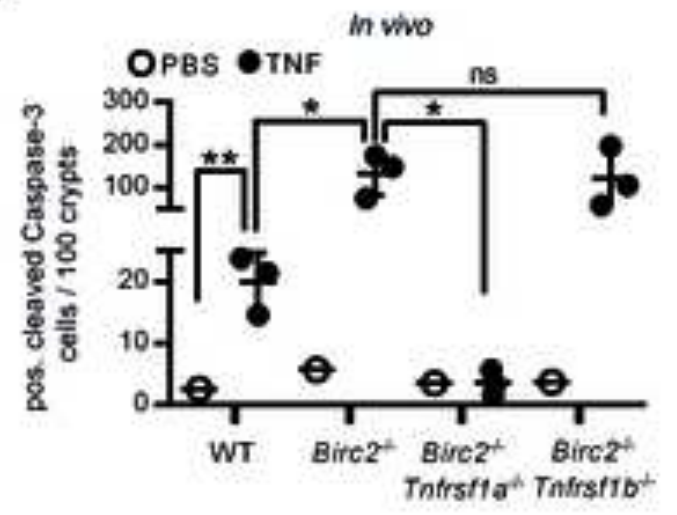


A

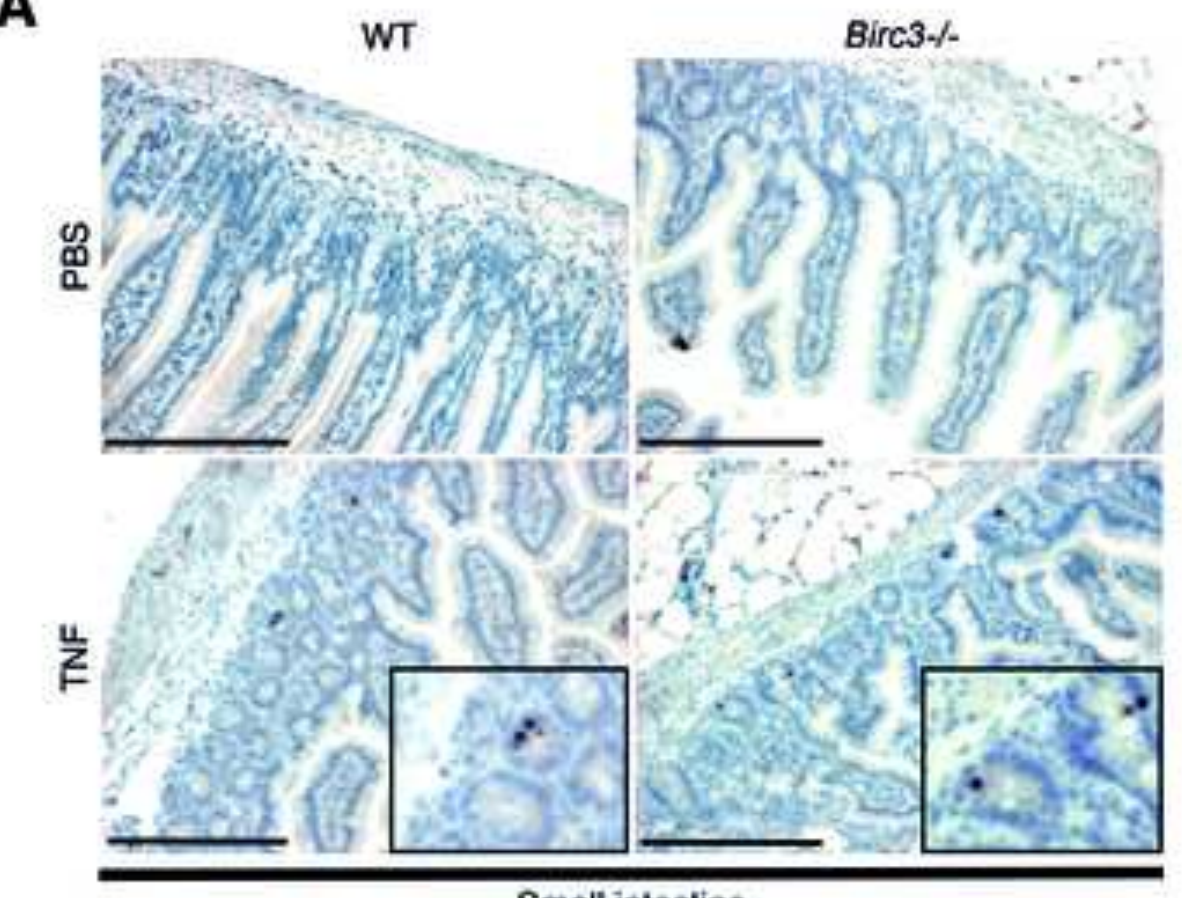

B

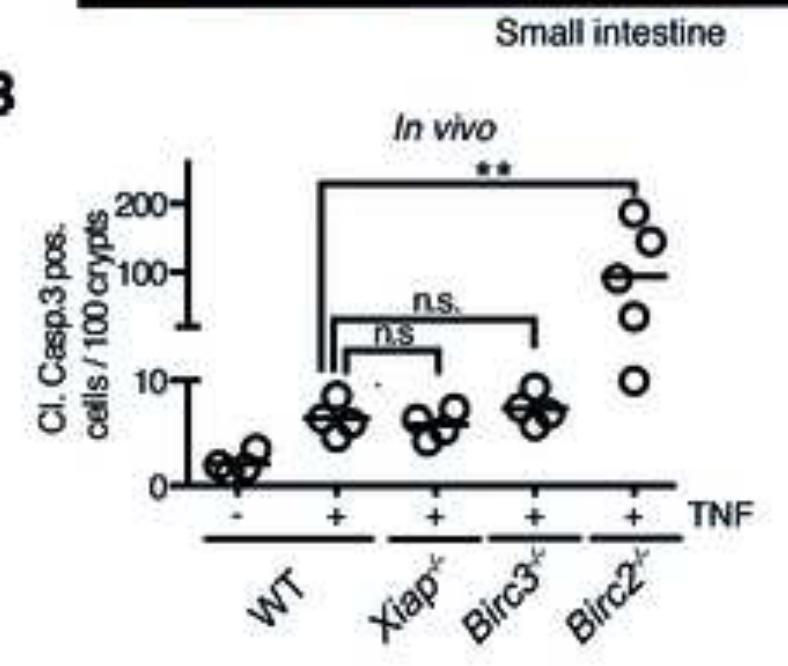

C

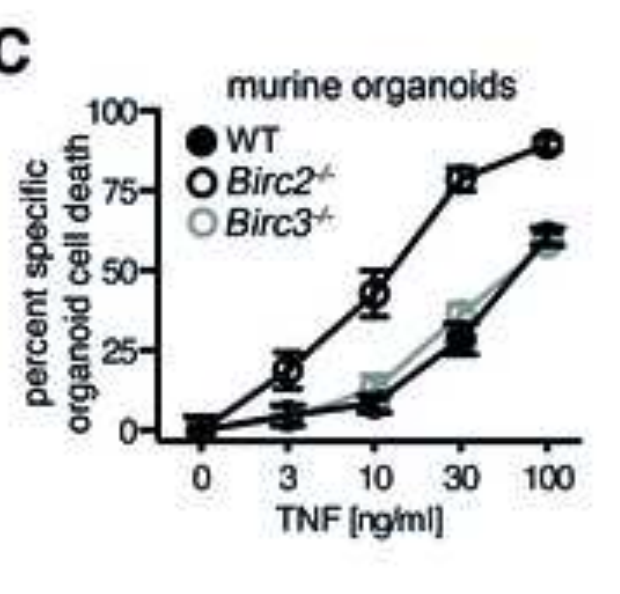

WT

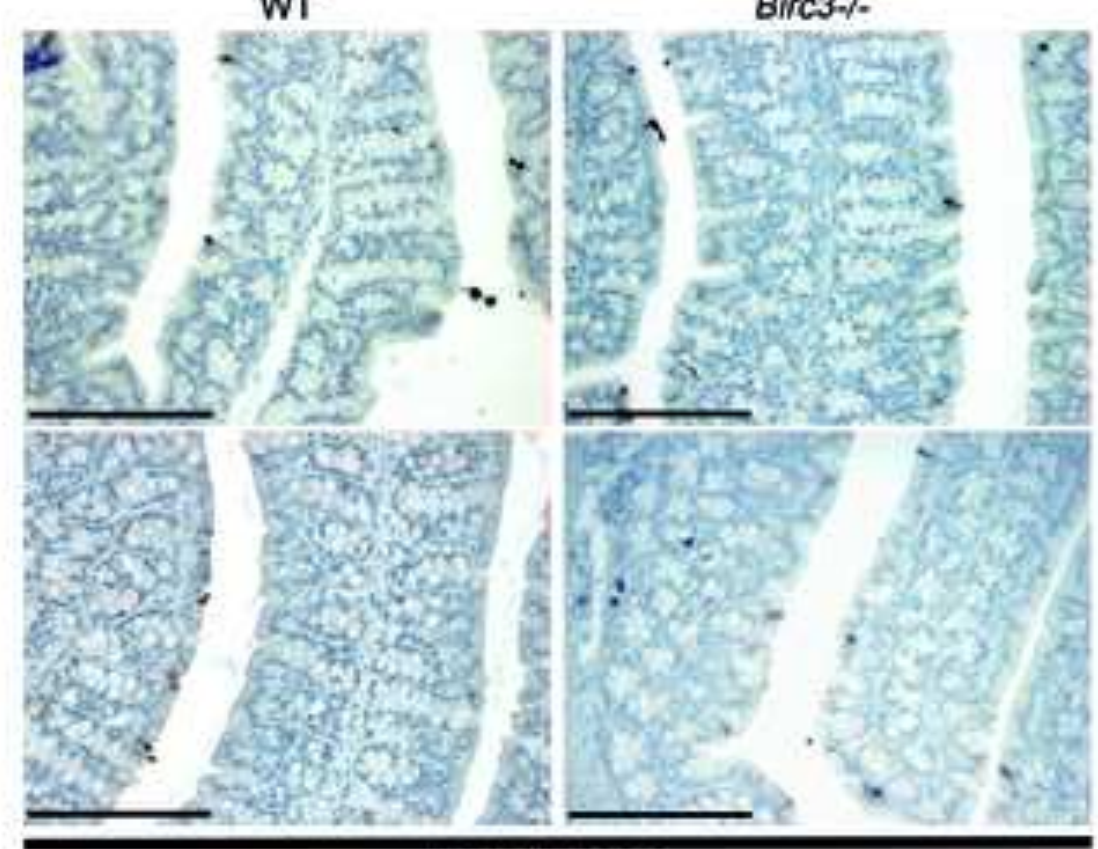

Large intestine 